\title{
Study on the Effect of Isotropic Initial Stress on the Anchoring Performance of Self-Expanding Bolts
}

\author{
Jie Liu $\mathbb{D}^{1,2}$ Hongya Li ${ }^{1}$, ${ }^{1,2}$ Yunzhou Li, ${ }^{1,2}$ Yunan Yang $\mathbb{D}^{1,2}$ Tao Sun, ${ }^{1,2}$ Rui Song $\mathbb{D}^{1,2}$ \\ and Rongqi Sun $\mathbb{B}^{1,2}$ \\ ${ }^{1}$ Hubei Geological Disaster Prevention and Control Engineering Technology Center, Yichang 443002, China \\ ${ }^{2}$ Key Laboratory of Geological Hazards on Three Gorges Reservoir Area, Ministry of Education, China Three Gorges University, \\ Yichang 443002, China
}

Correspondence should be addressed to Hongya Li; lhy_lihongya@163.com

Received 8 December 2020; Revised 17 January 2021; Accepted 20 February 2021; Published 11 March 2021

Academic Editor: bingxiang yuan

Copyright (C) 2021 Jie Liu et al. This is an open access article distributed under the Creative Commons Attribution License, which permits unrestricted use, distribution, and reproduction in any medium, provided the original work is properly cited.

In order to study the anchoring performance of a new type of self-expanding, high-strength, precompression anchoring technology with a large amount of expansion agent $(\omega \geq 5)$ cement slurry as anchoring solids under confined surrounding rock conditions, a rock mass anchoring device and methods that simulate in situ stress are developed, and real-time monitoring of expansion stress and anchor pull-out tests are carried out. The results show that the internal interface stress has a loss effect over time, and the stress loss value shows a linear increase trend with the dosage, but the loss rate shows a linear decreasing relationship with the dosage. This paper defines the coordinated additional stress and obtains its temporal and spatial evolution law in the rock mass. It is pointed out that there is a lag time difference between the peak of internal interface stress and the peak of coordinated additional stress, explaining its mechanical mechanism from the perspective of stress transfer. The strong restraint of the sealing section of the anchor hole causes the anchor solid to form a "shuttle-shaped" microexpanded head with thin ends and a middle drum under the expansion stress. During the drawing process, the microexpanded head is "stuck" in the anchor hole and moves upward to form the unique "load platform effect" of the anchoring system. And the mechanical mechanism diagram of this effect is obtained. It is pointed out that this effect can greatly improve the ductility of the anchoring system and the ultimate energy consumption value of damage. A prediction model for the ultimate pull-out force of self-expanding bolts is established. It is pointed out that the initial confining stress value has an exponential effect on the ultimate pull-out force. It shows that the surrounding rock with strong confinement constraints can greatly increase the ultimate pull-out resistance of the bolt. The selfexpanding strengthening coefficient $\lambda$ and the surrounding rock stress influence coefficient $k$ are introduced, the bolt interface mechanics formula and energy equation of the self-expanding anchor system are established, and the feasibility of the formula is verified by the calculation example. It is concluded that the ultimate pull-out resistance of the anchorage with $\omega=30$ is increased by 3.38 times compared with the ordinary anchorage under the initial confining stress condition of $0.7 \mathrm{MPa}$, the prepeak displacement of the bolt is increased by 2.08 times, and the prepeak energy consumption of the anchoring system is increased by 7.34 times. The cost only increased by $0.023 \%$ based on the literature example.

\section{Introduction}

The function of the bolt support system is to anchor and reinforce the deep rock area of the underground cavern, which plays an important role in safety maintenance in the field of geotechnical engineering [1]. It has been a trend to develop high-strength bolts that adapt to different complex geological environments.
Some researchers started with anchoring materials and grouting methods, and carried out many related studies. Ordinary anchoring mortar is modified to enhance its anchoring performance. It is found that cement emulsion as an anchoring material can improve the early strength of anchor rods in field tests and laboratory tests [2]. The anchoring performance of gypsum-bauxite mortar is increased by $39.6 \%$ compared with ordinary mortar, and it has good 
fluidity, quick-setting, microexpansion, early strength, and high strength performance [3]. By adding a certain amount of rigid particles to the grouting material to enhance the shear strength of the interface [4], in other words, the anchoring agent with high sand content and the surrounding rock with good integrity can effectively improve the anchoring force to the surrounding rock [5]. In the soft cracked rock support around the deep roadway, a high-pressure pretightening resin anchor with a compressed grouting body is proposed. Compared with the traditional tensile anchoring, the proposed high-pressure pretightening with precompressed grouting body resin anchoring has the ultimate bearing capacity [6]. At the same time, the grouting method can improve the friction force between the cement slurry and the rock and soil [7]. Compared with gravity grouting, rock-grouting contact stress with high pressure grout and cracks in the rock when the grout is injected into the ground under pressure will not only increase the diameter of the anchor solid and the bonding strength of the rock-grouting solid [8] but also significantly reduce the voids caused by bubbles in pressure grout anchor solid. Therefore, it has higher density and compressive strength, which significantly improves the pull-out resistance of pressure grouting anchors [9].

A lot of research achievements have also been made in optimizing the structure of the anchor rod to improve the pull-out resistance. An energy-absorbing anchor rod was developed based on the energy principle. The static tensile test and the dynamic drop test showed that the energyabsorbing anchor rod has a large load-bearing and deformation capacity. By absorbing large amounts of energy to maintain the stability of the surrounding rock, it counteracts the explosiveness and compression of the rock in the process of underground excavation [10]. Using a new type of carbon fiber bamboo bolt as the anchor rod, the failure modes and anchoring performance of the carbon fiber Moso bamboo anchor rod under different anchoring lengths $L$ and anchor rod diameters were studied, and the failure modes and ultimate bearing capacity of the carbon fiber bamboo anchor rod in different test batches were obtained [11]. In order to solve the serious stability problem caused by the high stress in the surrounding rock, a new yield rock bolt is proposed-the tensile and compression coupling yield rock bolts that can significantly improve the ultimate bearing capacity of the anchored section and adapt to the large deformation of rock mass [12]. Some researchers studied the ultimate support effect of super prestressed bolts, which can improve the stress distribution of the surrounding rock and help optimize the support parameters and improve the bearing capacity of the roof [13]. The researchers used numerical methods to study the anchorage performance of inflatable steel pipe rock anchors. The expansion of the inflatable steel pipe anchor rod, the distribution of contact stress, and the change of the average contact stress and contact area during installation are analyzed [14]. A new type of inflatable anchorage system and carrying out research on its anchoring performance was proposed. It also has the advantages of being recyclable, reusable, and rapidly forming anchoring force [15]. Based on the transparent synthetic soil, an improved three-dimensional displacement measurement system is developed, which simulates the high stress field by using the theory that the seepage force increases the effective dead weight stress of the soil, providing a new method for monitoring the interaction between rock and soil mass, and improving the supporting structure $[16,17]$.

An expansion agent is a very effective mixture to prevent cracking due to spontaneous drying shrinkage [18]. Tae and Kwon summarize the chemical composition of calcium sulfo-aluminate and lime-based expansion agents, and discuss the expansion mechanism, chemical prestress, and typical properties of expansive cement concrete [19]. A mathematical model of spontaneous deformation of concrete with $\mathrm{MgO}$ as an expansion agent is established, which clearly reveals the characteristics of spontaneous deformation of concrete with $\mathrm{MgO}$ as an expansion agent [20]. The effects of calcination conditions on the microstructure, hydration activity, and expansion performance of MgO-type expansion agent MEA were studied, and a new MEA expansion model was proposed [21]. Based on isothermal calorimetry and thermo gravity analysis, the hydration behavior of CEA in cement slurry was studied, the hydration kinetics was analyzed, the apparent hydration activation energy of CEA was calculated, and a chemical-mechanical model was established to predict the expansion performance and crack resistance of concrete containing the CEA agent [22]. When the amount of HCSA is $7 \%-8 \%$ of the weight of the adhesive material, it can provide favorable shrinkage compensation and early crack resistance, and the impact on the slump and compressive strength of SHRCC is negligible [23]. In order to reduce the shrinkage of HPC, it is found that the method combined with expansion agent and shrinkage reducing agent works well. The JCI model can be used to predict spontaneous shrinkage. Considering the influence of EA and SRA, the introduction of a correction factor can improve the accuracy of the JCI model [24]. HPC has the risk of early cracking due to the development of spontaneous shrinkage, and the addition of EXA can significantly reduce the spontaneous shrinkage and self-tensile stress [25]. Ultrahigh performance concrete (UHPC), such as a concrete filled steel tube, is prepared by using a combination of lightweight aggregate (LWA) and a $\mathrm{CaO}$ expansive agent (EA). The volume stability of UHPC by LWA and EA was evaluated systematically, and the expansion stress of the UHPC filled steel tube was determined [26]. Meanwhile, in order to ensure the excellent frost resistance of the external concrete of China Longtan Dam, a new type of roller compacted concrete containing $\mathrm{MgO}$ expansion agent (HNM) was used to obtain a durability coefficient exceeding D-300 [27]. In order to avoid excessive expansion of expansive agent concrete, the expansion accelerator (based on calcium sulfonate, CSA) and shrinkage reduction additive (super absorbent polymer, SAP, and shrinkage reduction agent, SRA) are combined to make the prestress of central concrete reach about 2.5-3 MPa, but the compressive strength of concrete is still about $100 \mathrm{MPa}$, and concrete has high freezing-thawing resistance [28]. Some researchers used slag as a calcium source to prepare high strength, alkali-activated coal stone slag cementing materials, and used high-performance 
concrete expansion agent, U-shaped expansion agent, to control the shrinkage rate [29]. In order to study the influence of the UEA and the MgO expansion agent on the fracture performance of concrete, it is pointed out that the development trend of fracture parameters of concrete varies with the curing age under different mixture ratios of UEA and $\mathrm{MgO}$ expansion agent based on SEM and XRD microscopic experiments [30].

At the same time, the expansion agent also plays an important role in replacing harmful conventional gas blasting technology. SCDA is a kind of cement powder, mainly composed of quick lime $(\mathrm{CaO})$, which will cause huge expansion pressure when it comes into contact with water under limited conditions. Therefore, by injecting SCDA into the borehole of the rock mass, the huge expansion force generated by the reaction can be used for the crushed stone [31]. However, in the deep underground environment, the expansion pressure generated by SCDA is slow and the fracturing will be significantly delayed [32]. Nonexplosive methods have advantages in reducing noise, vibration, and dust emission during the demolition of large concrete structures. Silent chemical removal agent (SCDA) is injected into the holes drilled in the concrete structure. The purpose of concrete demolition is achieved by the crack initiation and propagation caused by slow expansion of SCDA [33]. Based on the test of 33 kinds of nonreinforced blocks with different strengths with expansion fracturing agent, the initiation and propagation of cracks were analyzed, and it was pointed out that the material with higher strength needed more time to produce the first crack [34]. For underwater rock fracturing, a series of experiments were conducted to study the fracturing performance of the improved SCDA in saturated rock mass. It was found that the initiation time of fractures and the total fracture network length and volume depend on the saturated pore fluid of the rock. And, the direction of the fracture also changes according to the saturated fluid [35]. In order to understand the fracture performance of SCDA under the condition of the in situ stress prevalent in the ISL environment, some researchers used particle flow code (PFC3D 5.0) to generate a $3 \mathrm{D}$ numerical model of SCDA charge and studied the fracture mechanism of SCDA charge under various confining pressures [36]. In order to solve the problem that conventional silent chemical dismantling agent (SCDA) is difficult to use in wet or upper inclined borehole, the components of conventional SCDA are optimized, and an innovative SCDA filter element, which is called the selfexpanding filter element (SSC) is proposed. The expandability and mechanical properties of the new type of SSC are studied [37].

The authors add an expansive agent with a high content (more than 5\%) into the cement slurry and use it as an anchoring material to propose a self-expanding bolt anchoring technology. As shown in Figure 1, the chemical reaction equation is as follows: (1) $\mathrm{CaO}+\mathrm{H}_{2} \mathrm{O}=\mathrm{Ca}(\mathrm{OH})_{2}$; (2) $\mathrm{Al}_{2} \mathrm{O}_{3}+3\left(\mathrm{CaSO}_{4} \cdot 2 \mathrm{H}_{2} \mathrm{O}\right)+3 \mathrm{Ca}(\mathrm{OH})_{2}+23 \mathrm{H}_{2} \mathrm{O}$

$=3 \mathrm{CaO} \cdot \mathrm{Al}_{2} \mathrm{O}_{3} \cdot 3 \mathrm{CaSO}_{4} \cdot 32 \mathrm{H}_{2} \mathrm{O}$ (ettringite). The volume of the generated ettringite solid phase expands to about 2 times its original size without lateral constraints [32]. Under the constraint of the surrounding rock of the pore wall, the enlarged volume generates huge expansion stress. Meanwhile, the anchor solid is preloaded by the constraint reaction force of the surrounding rock, which greatly increases the interface shear force and thus significantly increases the pulling force.

In this paper, the expansion stress evolution law, drawing failure characteristics, ultimate tensile force, and interface mechanics model of self-expanding bolt anchorage system under isotropic ground stress environment will be further studied to lay a foundation for the application and popularization of the technology.

\section{Research and Development of Experimental Scheme and Device}

2.1. Research and Development of Test Equipment. The authors propose a device and method for rock anchoring under simulated ground stress conditions (invention patent number: CN201711079426.0) as shown in Figure 2, and the detailed structure and description of the device are shown in Figure 3.

\subsection{Test Scheme}

(1) Purpose of the test

The evolution law and prediction model of the pullout force of self-expanding anchors under different lateral constraints in sandstone slopes are studied, and the loss effect of expansion stress and its mechanical mechanism are explained, providing technical support for improving self-expanding anchoring technology.

(2) Test process

Sample preparation: the preliminary field test as shown in Figure 4 shows that the expansion stress was transmitted by $100 \mathrm{~mm}$ in the sandstone and the loss is as high as $85 \%$; so, the sandstone taken from a sandstone slope in Zigui County, three Gorges Reservoir area, is made into $200 \times 200 \times 200 \mathrm{~mm}$ surrounding rock samples.

Stress sensor layout: stress sensors are arranged on the inside and outside interface of the sample, as shown in Figure 5.

Initial stress setting: the sandstone slope is about 33 meters high, and the maximum value of ground stress after conversion is $0.7 \mathrm{MPa}$; so, the four initial stress values of $0,0.2 \mathrm{MPa}, 0.4 \mathrm{MPa}$, and $0.7 \mathrm{MPa}$ are taken, respectively.

Anchor bolt casting: under each initial stress confinement, the amount of expansion agent in the expanding cement slurry increased from $\omega=0$ to $\omega$ $=30$ with an increment of $\Delta \omega=5$; the upper and lower ports are sealed with $25 \mathrm{~mm}$ of fast-setting and high-strength cement slurry to better restrain the axial strain caused by expansion, and the restraint rate can reach $90 \%$. The schematic diagram of anchor bolt casting is shown in Figure 6 . 


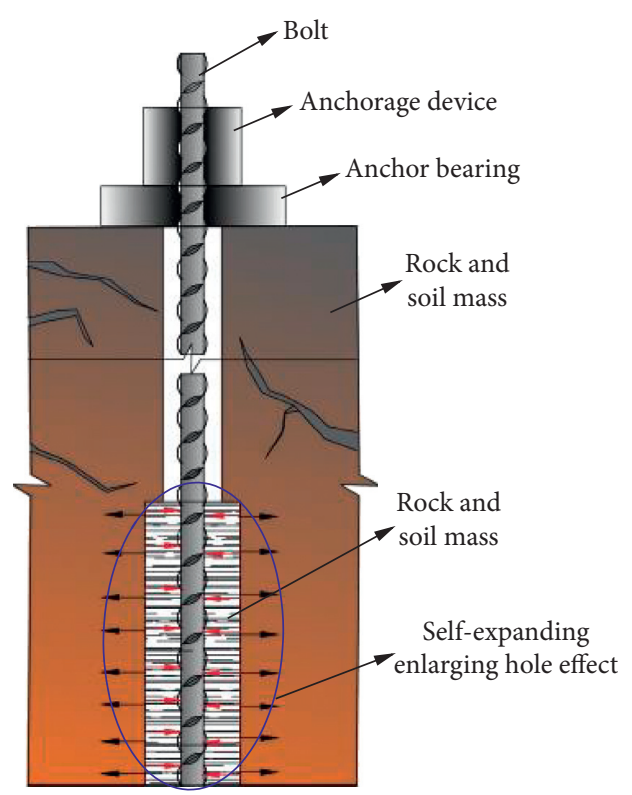

FIGURE 1: Schematic diagram of self-expanding, high-strength, precompression anchoring technology.

Stress monitoring: real-time detecting of boundary coordinated additional stress and internal interface stress, of which there is no initial confinement and only the internal interface stress is monitored after the pouring is completed.

Critical expansive agent content determination: if the sample is cracked when $\omega=a$, add the test of $\omega=$ $(2 a+5) / 2$ based on the dichotomy to determine the critical expansion agent content $\omega$ of the surrounding rock sample.

Pull out: after the expansion stress is developed steadily, a pull out test is carried out in the content.

\section{Analysis of the Evolution Law of Expansion Stress}

3.1. Analysis of Internal Interface Stress under Initial Limits. During the test, the monitoring data analysis shows that the laws of the four groups of test plans are similar, and the initial $0.7 \mathrm{MPa}$ lateral confined data are selected here for analysis. At the initial confinement of $0.7 \mathrm{MPa}$, the stress evolution curve at the internal interface is as shown in Figure 7.

3.1.1. Developmental Stage Division. According to the analysis in Figure 7, the internal interface stress is divided into three stages according to the time evolution trend of the expansion pressure. The internal interface stress increased continuously and reached its peak around $41 \mathrm{~h}$ in the growth stage: the internal interface stress showed a tendency to decrease during $41-47 \mathrm{~h}$ in the loss stage. The maximum fluctuation of internal interface stress is only $0.6 \%$ after $47 \mathrm{~h}$ in the stable stage, which can be considered as stable development of internal interface stress. This stage is the engineering operation stage.
3.1.2. Cause Analysis of Stress Loss. The difference between the internal interface stress peak value and the stable stress value in Figure 7 is defined as the stress loss. The internal interface stress loss statistics for each content is shown in Table 1, and the schematic diagram of the causes of the stress is shown in Figure 8.

(1) The analysis shows that radial contraction $\Delta l_{1}$ occurs after compression of the self-expanding anchor bolt. In this deformation, the stress $\Delta F_{1}$ will decrease over time when the surrounding rock sample is subjected to the action of expansion stress-tiny pore broadening occurs, resulting in extrusion deformation $\Delta l_{2}$ and corresponding stress loss $\Delta F_{2}$. At the same time, the whole anchorage system will have significant temperature change due to the reaction of the expansion agent, and the temperature stress will lead to the stress loss $\Delta F_{3}$, that is, the lost stress is $\Delta F=\Delta F_{1}+\Delta F_{2}+\Delta F_{3}$.

(2) Under the initial confinement scheme of $0.7 \mathrm{MPa}$, the absolute value of stress loss of each content, and the change curve of loss rate with content are shown in Figure 9.

The analysis shows that the stress loss value $\Delta F$ has a trend of linear growth with its content, while the loss rate has a linear decline with its content.

From an engineering point of view, the lower the stress loss rate is, the higher the engineering stability is. At the same time, it will also enhance the safety predictability of the formed protection structure and reduce the randomness.

3.1.3. Analysis of the Law of Interface Stress Peak. The relationship between the internal interface stress peak and the expansive agent content under various conditions is shown in Figure 10.

The following can be inferred from the analysis in Figure 10:

(1) It can be seen that the peak growth efficiency $\mu$ of the internal interface stress can be defined as follows:

$$
\mu=\frac{\Delta P_{f m}}{\Delta \omega},
$$

where $\mathrm{P}_{f m}$ is the peak growth value of internal interface stress, and $\Delta \omega$ is the increase in the value of expansion agent content.

(2) When $P_{f m} \geq 43.5 \mathrm{MPa}, \mu_{\mathrm{I}} / \mu_{\mathrm{II}}=0.525$ under the initial confining stress of $0.7 \mathrm{MPa}$ and $\mu_{\mathrm{I}} / \mu_{\mathrm{II}}=0.396$ under the initial confining stress of $0.4 \mathrm{MPa}$. Therefore, the relationship between the peak value of the internal interface stress and the content of the expansion agent can be divided into a high-efficiency growth stage and a low-efficiency growth stage, as shown in Figure 10.

(3) There is an obvious linear relationship between the internal interface stress peak and the content of 


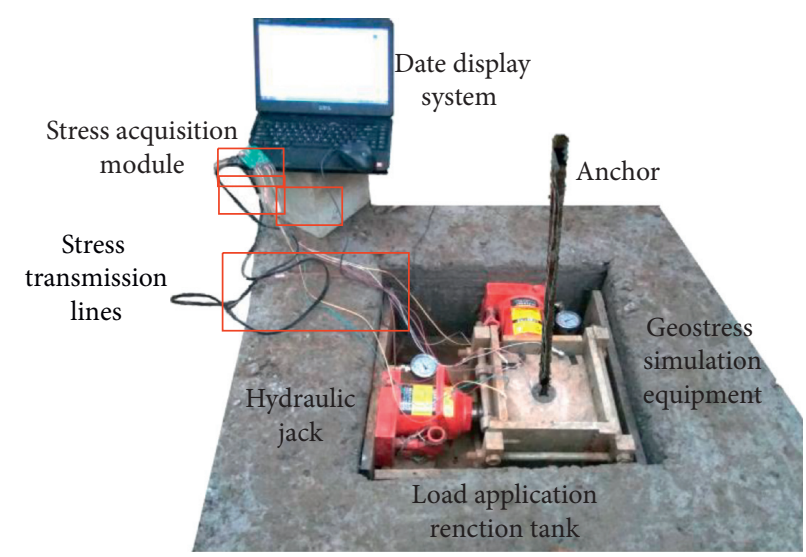

Figure 2: Device diagram of rock mass anchoring under ground stress.

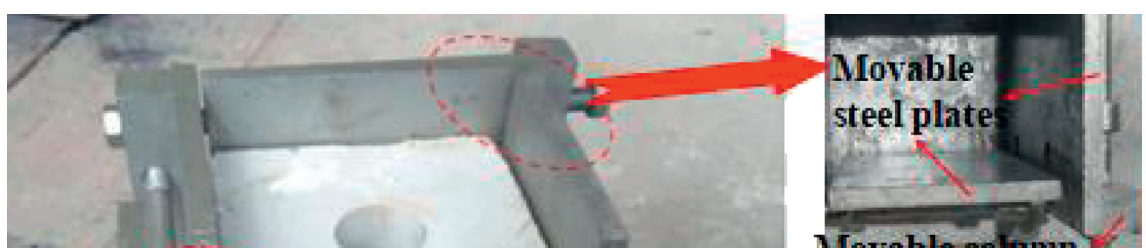

Movable column sliding freely with the movable steel plate, realizing two-way reaction loading

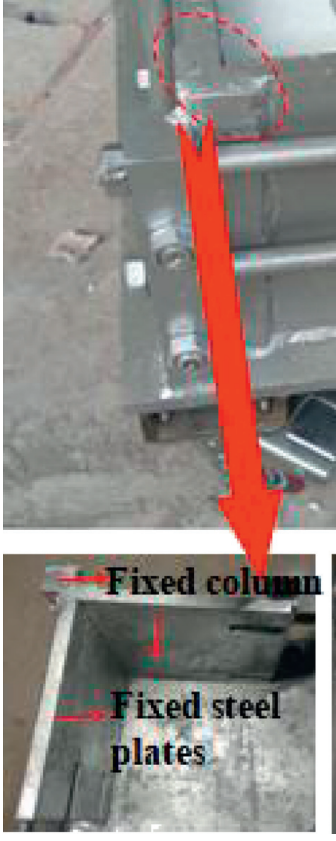

Fixed column: increasing the side limit stiffness to realize two-way reaction loading

Fixed steel plates: provides lateral stiffness
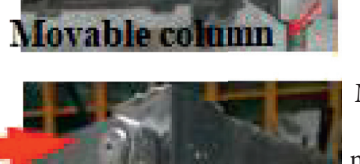

ovable column: any one-way movement, realize side limit adjustment

Figure 3: Detailed structure and explanatory diagram of in situ stress simulator.

expansive agent in the high-efficiency growth stage, which can be specifically expressed as

$$
P_{f m}=a \omega+b .
$$

In the formula, $P_{f m}$ represents the peak stress at the internal interface; arepresents the influence factors of the content of the expansive agent on the internal interface stress peak; $b$ represents the stress peak at the inner interface when $\omega=0$, where $b<0$ means the peak internal interface stress is 0 . 


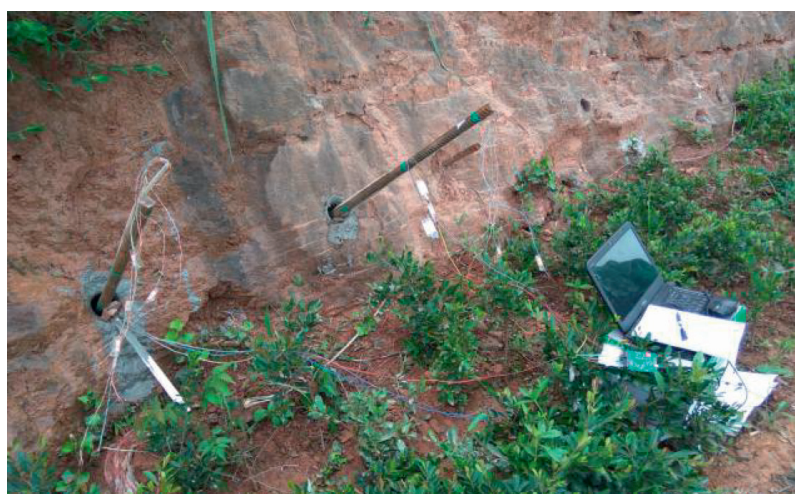

FIGURE 4: Field test chart of self-expansion anchoring.

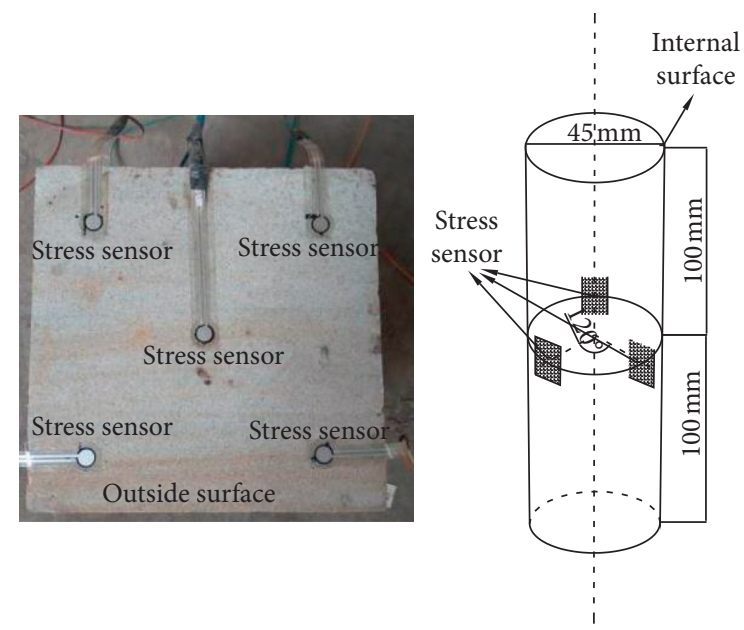

FIgURe 5: Physical picture of the surrounding rock.

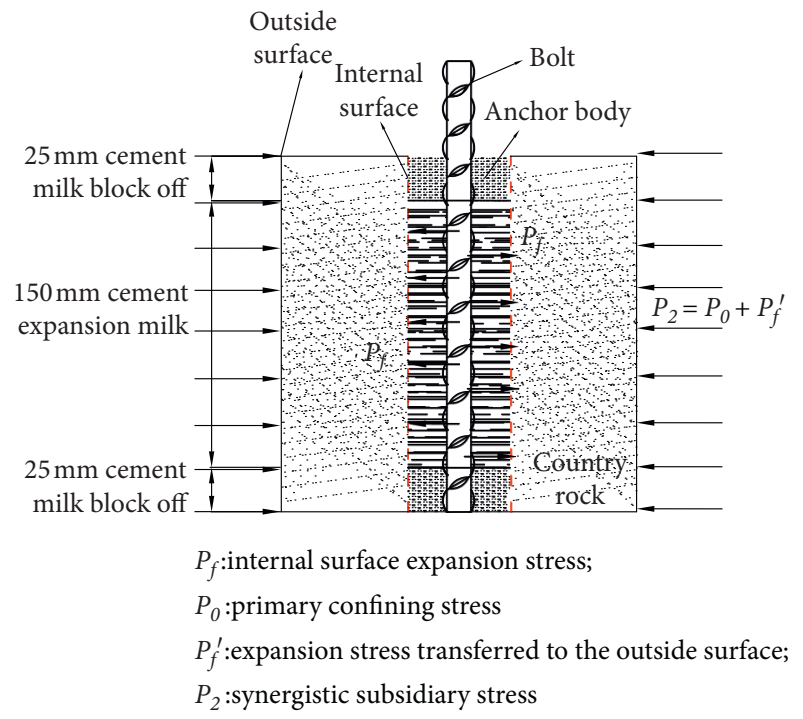

FIgURE 6: Schematic diagram of pouring anchors.

3.2. Analysis of Boundary Additional Cooperative Stress under Initial Confined Condition. The internal interface stress and the boundary additional coordinated stress of the initial

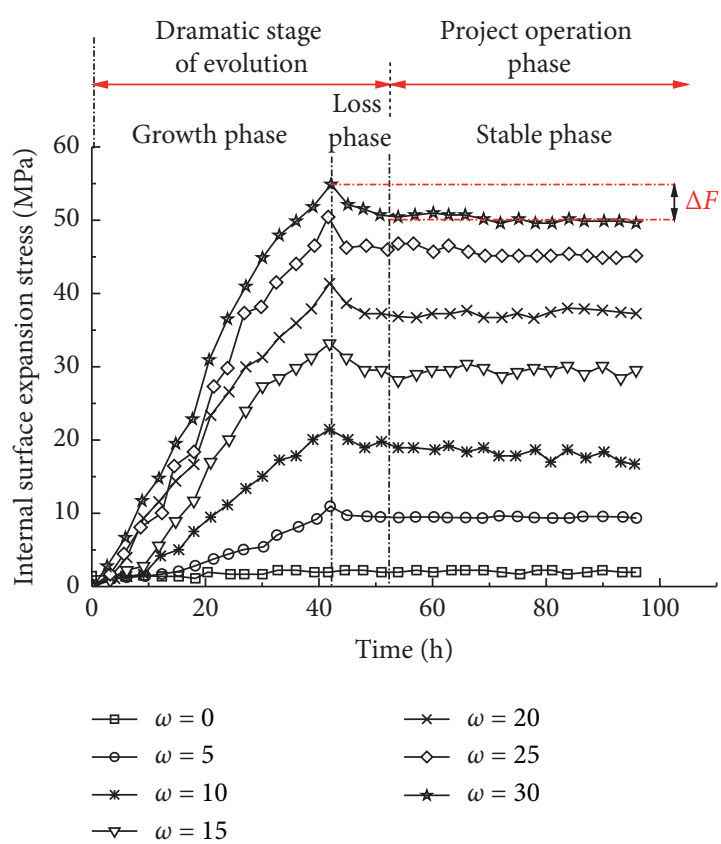

FIgURE 7: Internal interface stress evolution curve under the $0.7 \mathrm{MPa}$ initial scheme.

confinement of $0.7 \mathrm{MPa}$ are drawn to the same coordinate system, which is shown in Figure 11.

The following can be inferred from the analysis in Figure 11:

(1) It can be seen that there are also three stages of growth, loss, and stability in the boundary coordinated additional stress. It is due to the formula of the $P_{2}=P_{0}+P_{\mathrm{f} .}$. When the initial lateral limiting stress $P_{0}$ is determined, the boundary coordinated additional stress P2 is only affected by the expansion stress synergies' additional stress $P_{f}^{\prime}$ transferred to the outer boundary, so it is similar to the stress development stage at the internal interface.

(2) The peak time of the boundary coordinated additional stress lags behind the peak time of internal interface stress, and there is a "time lag." The original reason is that the expansion stress is transferred from the internal interface to the external surface, and it takes a certain time for the internal stress to reach a stable state. If the sample size is larger, the time difference will also increase. And the size effect of stress saturation should be fully considered in practical engineering application.

(3) Defining the time difference between the boundary coordinated additional stress peak and the internal interface stress peak as $\Delta h$. The relationship curve between lag time difference and initial confinement is obtained through statistics, which is shown in Figure 12.

It is found that there is a good linear relationship between the lag time difference and the initial confinement, which is shown as follows: 
TABle 1: Statistics of stress loss at various dosages under the initial confinement scheme of $0.7 \mathrm{MPa}$.

\begin{tabular}{lcccc}
\hline & & \multicolumn{2}{c}{ Indicators } & \\
Content (\%) & Peak pressure $(\mathrm{MPa})$ & The stable value $(\mathrm{MPa})$ & Pressure loss value $\Delta F(\mathrm{MPa})$ & 1.28 \\
\hline 5 & 10.94 & 9.46 & 3.27 & 11.70 \\
10 & 21.46 & 18.19 & 3.77 & 15.24 \\
Confine & 33.16 & 29.39 & 4.12 & 11.37 \\
20 & 43.37 & 39.25 & 4.92 & 9.96 \\
25 & 50.44 & 45.52 & 4.76 & 8.75 \\
30 & 54.90 & 50.14 & & 8.67 \\
\hline
\end{tabular}

The self-expanding anchor shrinks $\Delta l_{1}$ radially under pressure, resulting instress loss $\Delta F_{1}$, and temperature stress causes stress loss $\Delta F_{3}$

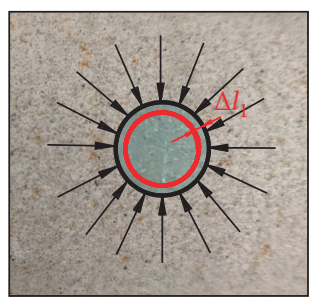

The country rock sample is squeezed and deformed by expansion stress $\Delta l_{2}$, resulting in stress loss $\Delta F_{2}$

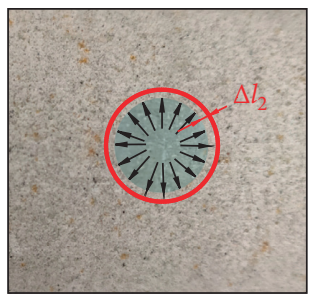

Figure 8: Schematic diagram of self-expanding anchor and surrounding rock stress.

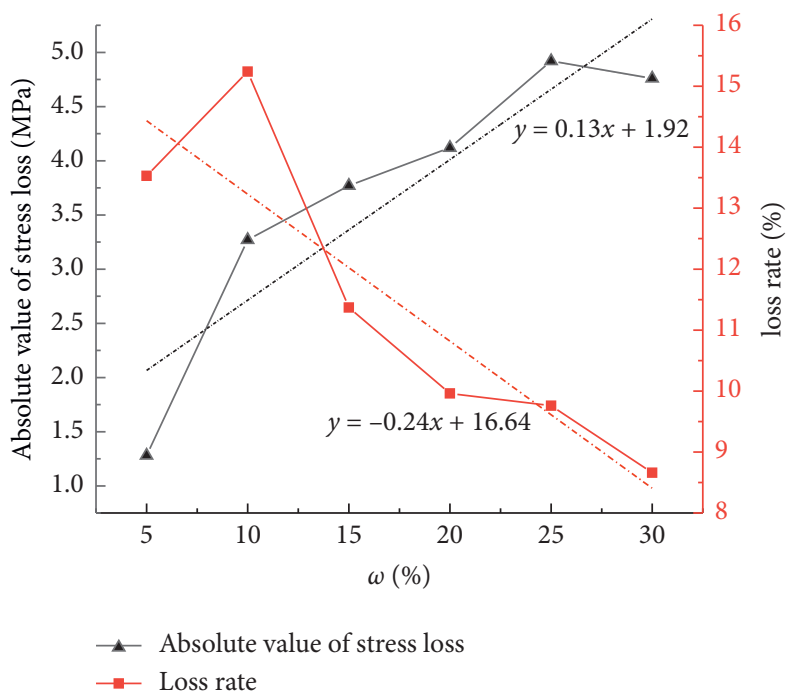

Figure 9: Statistical curve of stress loss.

$$
\Delta h=m p_{0}+n
$$

$\Delta h$ represents the time difference between the peak value of the boundary coordinated additional stress and the peak value of internal interface stress. $P_{0}$ is the initial lateral limiting stress $m$ and represents the attenuation factors of initial lateral limit to lag time difference, and $n$ represents the time it takes for the expansion stress to transfer to the outer boundary when $P_{0}=0$. It is shown that high confinement constraint can significantly improve the self-expansion performance and shorten the stress saturation time.
3.3. Fracture Stress Analysis of the Internal Interface without Initial Lateral Limit. It is found that the sandstone sample was split when the $\omega=0$ increased to $\omega=10$, which is shown in Figure 13. The sandstone samples with other dosages were not cracked. Then adding the test of $\omega=7.5$. The stress evolution curve of the internal interface at the four content levels is shown in Figure 14.

According to the analysis, it is found that a crack appears from the inside to the outside of the rock in Figure 13 when $\omega=10$ without lateral constraint, and the stress is released, resulting in a sharp drop of the stress at the internal interface in Figure 14. This indicates that when applied to similar 


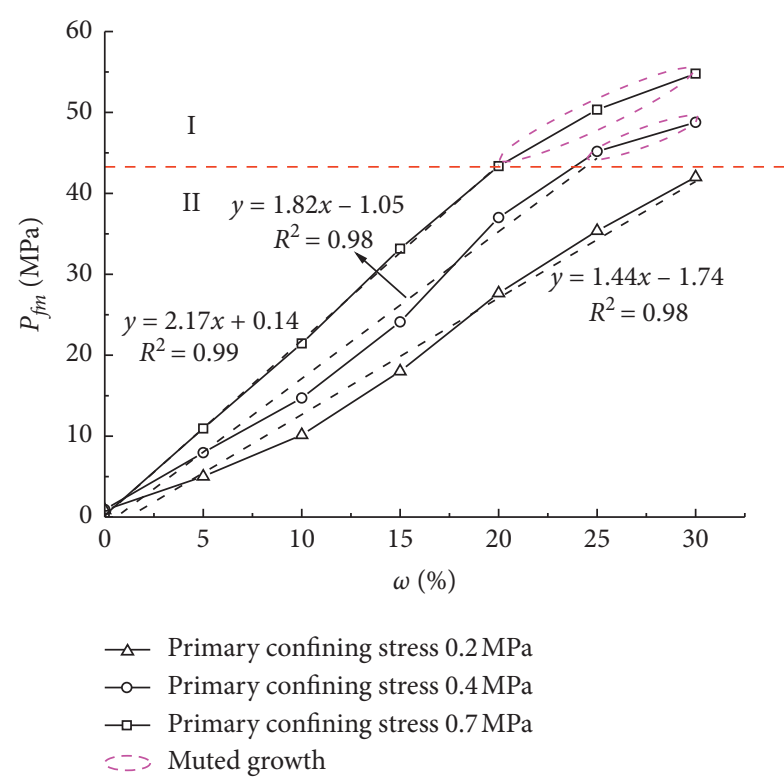

Figure 10: Variation of the internal interface stress peak with the expansion agent content under different confinement schemes.

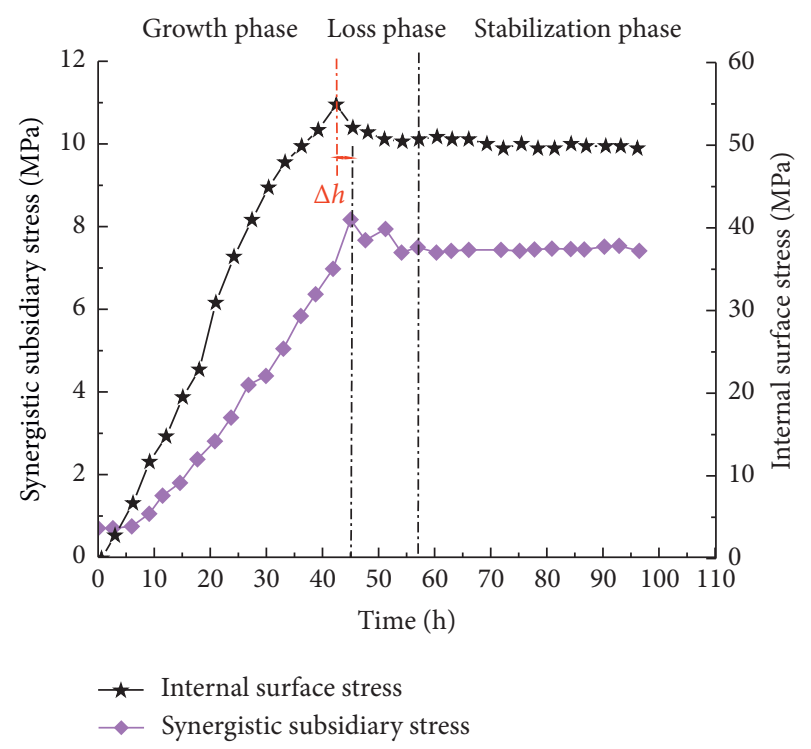

FIgURE 11: Evolution curve of internal interface stress and boundary additional coordinated stress.

unconfined sandstone anchoring, the fracture stress at the internal interface is $10.85 \mathrm{MPa}$, that is, the content of the optimal expansive agent for similar unconfined sandstone anchoring is less than 10 , otherwise the sandstone will be fractured and the anchoring will fail.

3.4. The Analytical Model of Stress Distribution Prediction of the Self-Expanding Anchor Solid on the Surrounding Rock Is Established. Starting from the stress distribution of the surrounding rock, the stress distribution law of the surrounding rock under the joint action of expansion stress and



FIGURE 12: Relationship between lag time difference and initial limit.

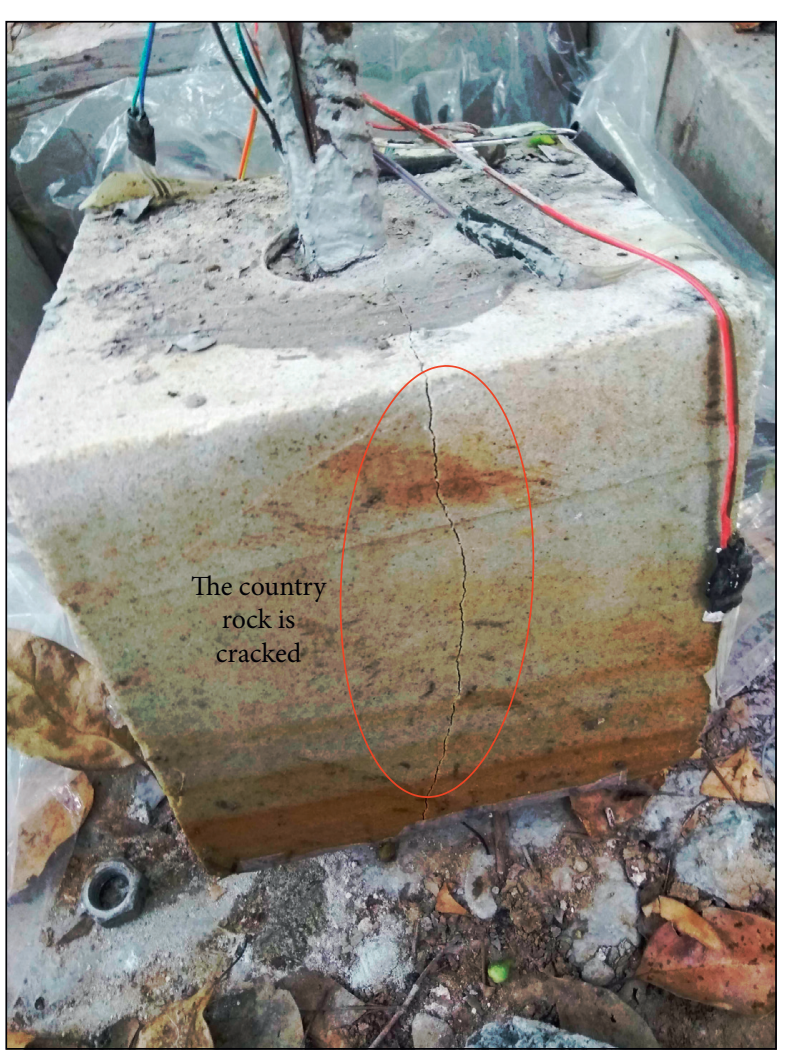

Figure 13: Sample rupture diagram.

initial stress is considered. Now carry on the deduction analysis as follows.

3.4.1. Overview of In Situ Initial Stress Distribution of Surrounding Rock. When drilling inward at the bottom of a rock slope, the influence of axial stress $\sigma_{y}$ along the anchor bolt is not considered, and the problem of plane strain can be simplified. According to the Poisson effect of the 


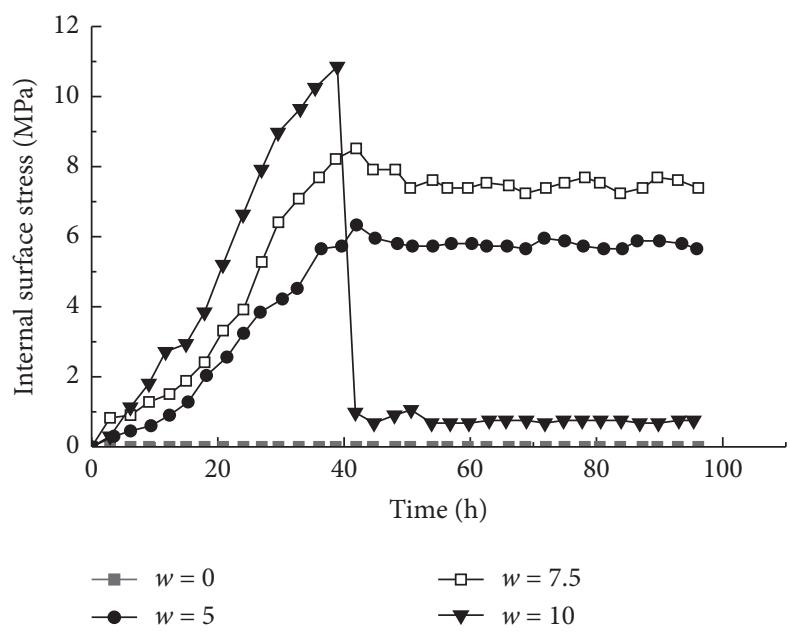

Figure 14: Curve of internal interface stress evolution without initial confinement scheme.

surrounding rock, the two horizontal principal stresses at the borehole are as follows:

$$
\sigma_{x}=\sigma_{z}=\frac{\mu}{1-\mu} \gamma H+\sigma_{H}
$$

where $\gamma$ is the gravity of the surrounding rock over the borehole, $H$ is the buried depth of the borehole, $\mu$ is Poisson's ratio of the surrounding rock over the borehole, and $\sigma_{H}$ is the horizontal tectonic stress.

3.4.2. The Stress Model of the Surrounding Rock under the Action of Self-Expanding Anchor Solid. It is assumed that the force of the expansive anchor solid on the surrounding rock is regarded as uniform force, and the surrounding rock is an isotropic and homogeneous elastomer. The above mechanical system is explained by the superposition of the stress concentration problem at the edge of a circular hole in elastic mechanics and the uniform pressure problem of the circular hole in an infinite medium, as shown in Figure 15.

3.4.3. Establishment of the Initial Stress Formula of Surrounding Rock. Based on the above theoretical model, the initial internal stress of the surrounding rock before the action of the self-expanding anchor is as follows:

$$
\begin{aligned}
\sigma_{r 1} & =\left[\frac{\mu}{1-\mu} \gamma H+\sigma_{H}\right]\left(1-\frac{r^{2}}{R^{2}}\right), \\
\sigma_{\theta 1} & =\left[\frac{\mu}{1-\mu} \gamma H+\sigma_{H}\right] \cdot\left(1+\frac{r^{2}}{R^{2}}\right), \\
\tau_{\theta 1} & =0,
\end{aligned}
$$

where $\sigma_{r 1}$ is the initial radial stress of the surrounding rock on the borehole section, $\sigma_{\theta 1}$ is the initial circumferential stress of the surrounding rock on the borehole section, $\tau_{\theta 1}$ is the initial shear stress of the surrounding rock on the borehole section, and $R$ is the distance between the surrounding rock and the borehole center.
3.4.4. Establishment of the Stress Formula of the Surrounding Rock Only under the Action of Self-Expanding Anchor Solid. The stress generated by the self-expanding anchor solid on the surrounding rock without initial stress is as follows:

$$
\begin{aligned}
& \sigma_{r 2}=q \frac{r^{2}}{R^{2}}, \\
& \sigma_{\theta 2}=-q \frac{r^{2}}{R^{2}}, \\
& \tau_{\theta 2}=0,
\end{aligned}
$$

where $\sigma_{r 2}$ is the radial expansion stress on the borehole section, $\sigma_{\theta 1}$ is the circumferential expansion stress on the borehole section, and $\tau_{\theta 1}$ is the expansion shear stress on the borehole section.

3.4.5. Analytical Model for Stress Prediction of the Surrounding Rock under the Action of the Self-Expanding Anchor Solid. By using equations two to seven and the superposition principle, the stress of the surrounding rock around the borehole can be obtained as follows:

$$
\begin{aligned}
& \sigma_{r}=\frac{1}{2}\left[\frac{1}{1-\mu} \gamma H+\sigma_{H}\right]\left(1-\frac{r^{2}}{R^{2}}\right)+q \frac{r^{2}}{R^{2}}, \\
& \sigma_{\theta}=\frac{1}{2}\left[\frac{1}{1-\mu} \gamma H+\sigma_{H}\right]\left(1+\frac{r^{2}}{R^{2}}\right)-q \frac{r^{2}}{R^{2}}, \\
& \tau_{\theta}=0
\end{aligned}
$$

where $\sigma_{r}$ represents the radial expansion stress on the borehole section, $\sigma_{\theta}$ represents the hoop expansion stress on the borehole section, and $\tau_{\theta}$ represents the expansion shear stress on the borehole section. And equations (11)-(13) can be used to predict the stress distribution of the surrounding rock at different locations under the action of the selfexpanding anchor solid. 

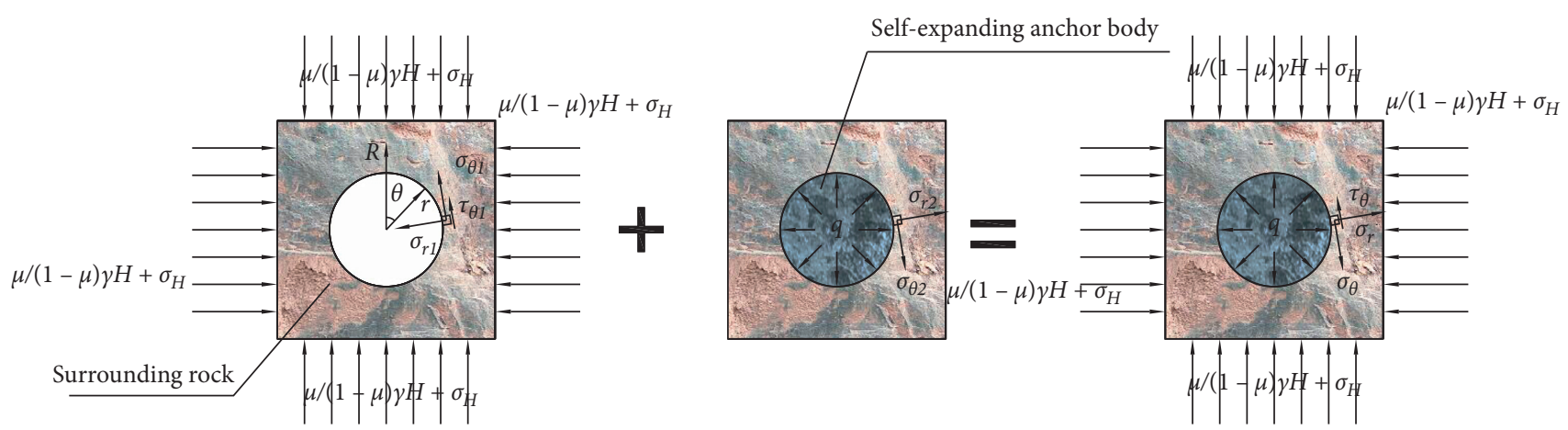

FIGURE 15: Superposition principle of stress distribution of the surrounding rock under the self-expanding anchor body.

\section{Analysis of Rock Anchoring Pull-Out Tests Under Different Coordinated Additional Stress Conditions}

4.1. Analysis of Damaged States and the Load-Displacement Curve. Pull-out tests are carried out on samples with different contents of the expansive agent under the four initial confinement schemes mentioned above, and loaddisplacement curves of the expansive agent with different contents are drawn according to the pull-out force measured by the pull-out test and anchor displacement test data. The failure modes in the experiment mainly include the interface failure between anchor bolt and the surrounding rock when $\omega \leq 10$ and the interface failure between anchor and anchor bolt when $\omega>10$. Due to the limited length, the damage pattern is only analyzed in the case of $\omega=10$ and $\omega=30$ under each initial confinement.

4.1.1. Analysis of Interface Failure between the Anchor Bolt and the Surrounding Rock. In the same coordinate system, load-displacement curves, failure modes, and mechanisms corresponding to $c w=10$ under four initial lateral limits are drawn, as shown in Figure 16.

(1) The analysis shows that the anchor displacement $X$ increases sharply after the pull-out loading $P \geq F u$, the change of the drawing load $P$ is only $10.08 \%$, and the load-displacement curve has a unique flat curve segment similar to the step, which is defined as the "load platform effect."

(2) Analysis of the cause of "load platform effect." Because the upper and lower anchor holes are sealed with plain cement, the anchor bolt forms a "spindle" microexpanding head with thin ends and a middle drum at both ends under the expansion stress, and the microexpanding head "gets stuck" in the anchor hole and moves up continuously during the drawing process, forming a platform effect, where the rise height of the microexpanding head $X$ is equal to the platform length $X$.

(3) This effect shows that the failure of the selfexpanding bolt has obvious ductility, the failure limit energy consumption value is greatly increased, and the safety reserve is large, which can be used in seismic engineering.

The platform characteristics in Figure 16 are counted, and the results are shown in Table 2.

(1) The analysis shows that the platform length $X$ and platform slope $k^{\prime}$ show a decreasing trend with the increase of the initial confining stress $P_{0}$. The reason is that the initial confining stress restricts the development of the microexpansion head, which not only causes the upward movement height $X^{\prime}$ of the microexpansion head to be stuck in the anchor hole to decrease but also increases the drop of the pull-out loading.

(2) With the increase of the initial confining stress $P_{0}$, the strength of the interface between the anchor bolt and the surrounding rock gradually increases, so the ultimate pull-out capacity $F_{u}$ shows an increasing trend.

4.1.2. Analysis of Interface Failure between the Anchor Body and the Anchor Bolt. At the same time, the load-displacement curve diagram under different content of the expansion agent is drawn based on the pull-out force measured by the pull-out test and the anchor rod displacement test data. The stage before the maximum pull-out loading is defined as the prepeak growth section. The drawing curve, failure morphology, and mechanism corresponding to $\omega=30$ under the initial confinement of $0.4 \mathrm{MPa}$ are shown in Figure 17.

(1) The analysis shows that expansion stress greatly increases the shear strength of the inner interface and the strength of the anchor body. The pull-out force transmitted to the inner interface is less than the shear yield strength of the inner interface and the strength of the anchor bolt, and it is not enough to damage the inner interface and the anchor bolt, so that the rod body shear failure occurred at the anchor solid interface and the anchor rod was pulled out.

(2) There is no "load platform effect" in the drawing curve, which immediately drops after reaching the peak load. However, the distance of the prepeak growth section exceeds $50 \%$ of the anchorage length, 


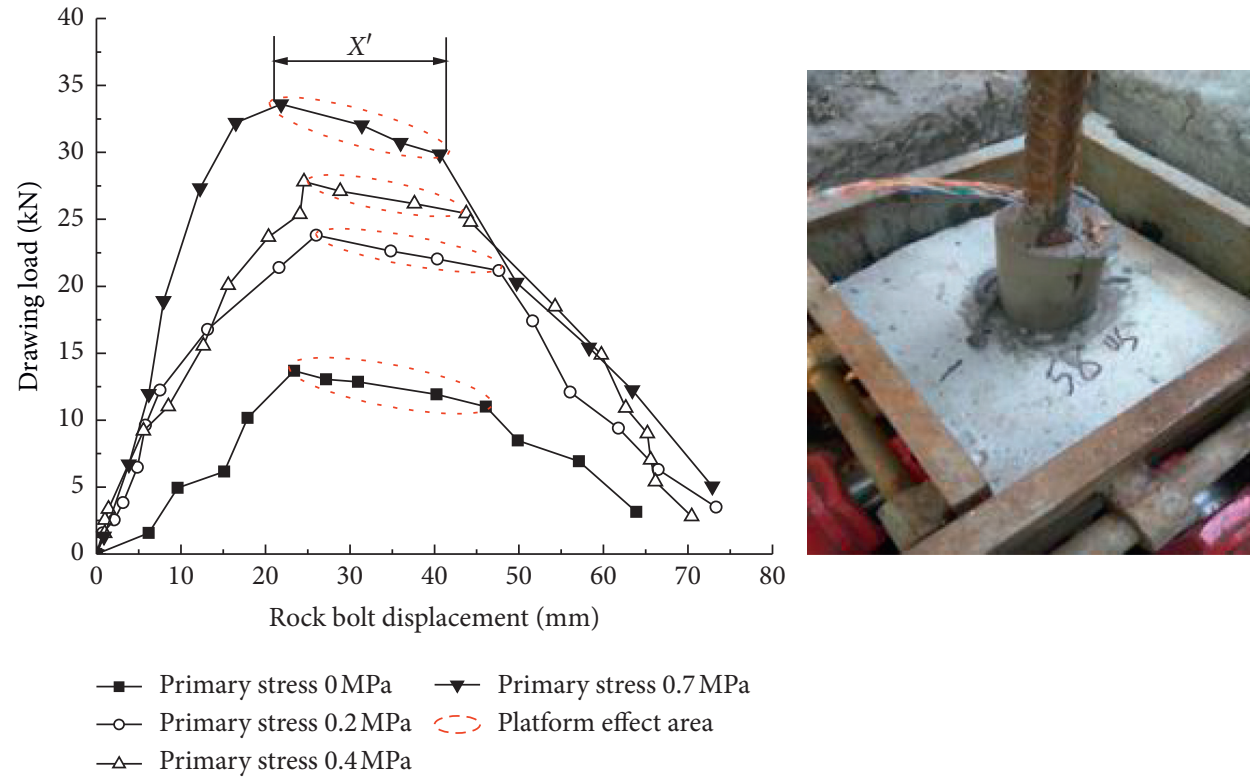

(a)

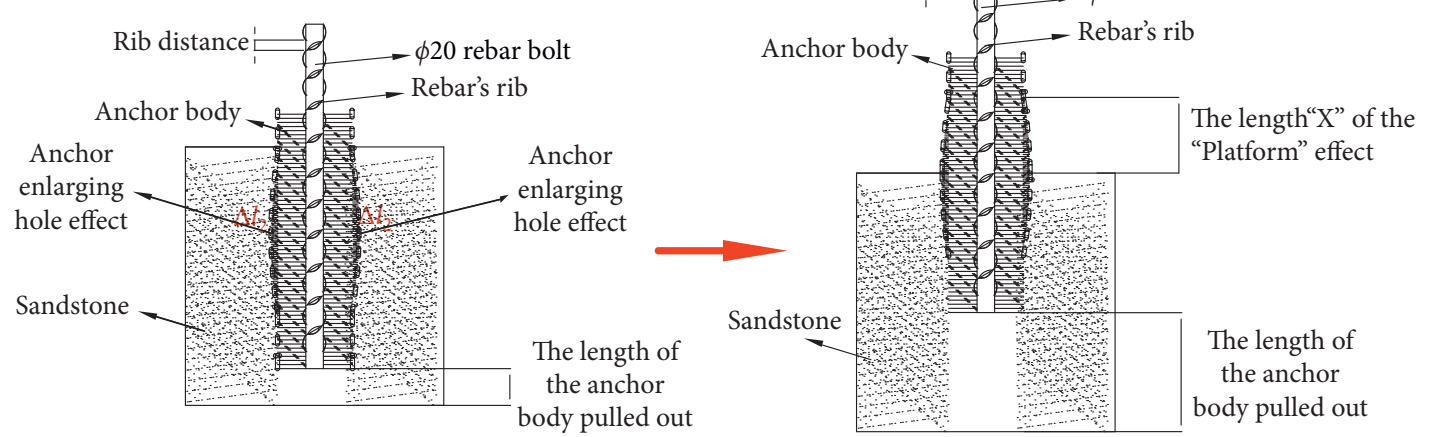

(b)

FIGURE 16: Load-displacement curve, failure morphology, and mechanism diagram of interface between the anchor and the surrounding rock. (a) Drawing curve and damage pattern diagram. (b) Failure mechanism diagram.

TABLE 2: Platform characteristics statistics.

\begin{tabular}{|c|c|c|}
\hline \multicolumn{3}{|c|}{ Characteristics of the item } \\
\hline Confining stress $(\mathrm{MPa})$ & Platform length $X(\mathrm{~mm})$ & Platform slope $K^{\prime}$ \\
\hline 0 & 22.703 & 0.118 \\
\hline 0.2 & 21.623 & 0.122 \\
\hline 0.4 & 19.197 & 0.124 \\
\hline 0.7 & 18.777 & 0.199 \\
\hline
\end{tabular}

indicating that the pull-out force is still increasing during the sliding process of the bolt.

(3) According to the analysis of the reasons for the increase of tensile force, in the drawing process, the dilatancy debris of the steel bar interface gathers between the rib teeth of the steel bar to form a dense enlarged head, and with the pulling out of the anchor rod, the expanding head at the bottom of the steer bar has an increasing trend. Only when the resistance of the expanding head is not enough to resist the pull-out loading will it be destroyed, that is, it will fall rapidly after the peak value.

4.2. Analysis of the Law of Ultimate Pull-Out Capacity. The peak pull-out loading corresponding to each expansion agent content under different initial confinement schemes is selected as the ultimate pull-out capacity, and the change curve of the lower bound pull-out capacity under different additional stress conditions with the content of the expansive agent is drawn, as shown in Figure 18. 


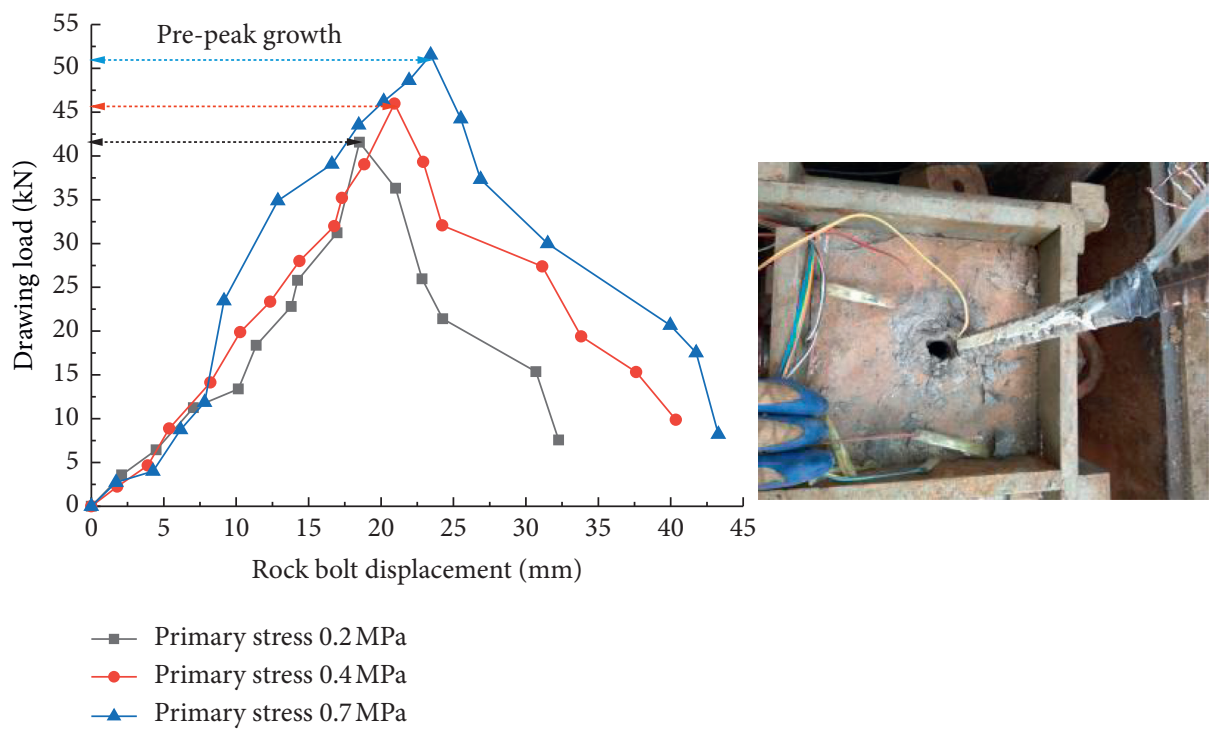

(a)

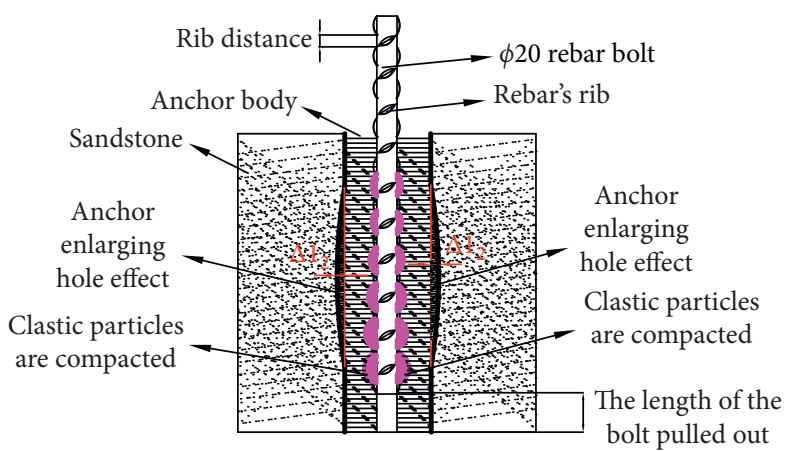

(b)

FIGURE 17: Load-displacement curve, failure mode, and mechanism diagram of anchor interface.(a) Drawing curve and failure pattern diagram. (b) Failure mechanism diagram.
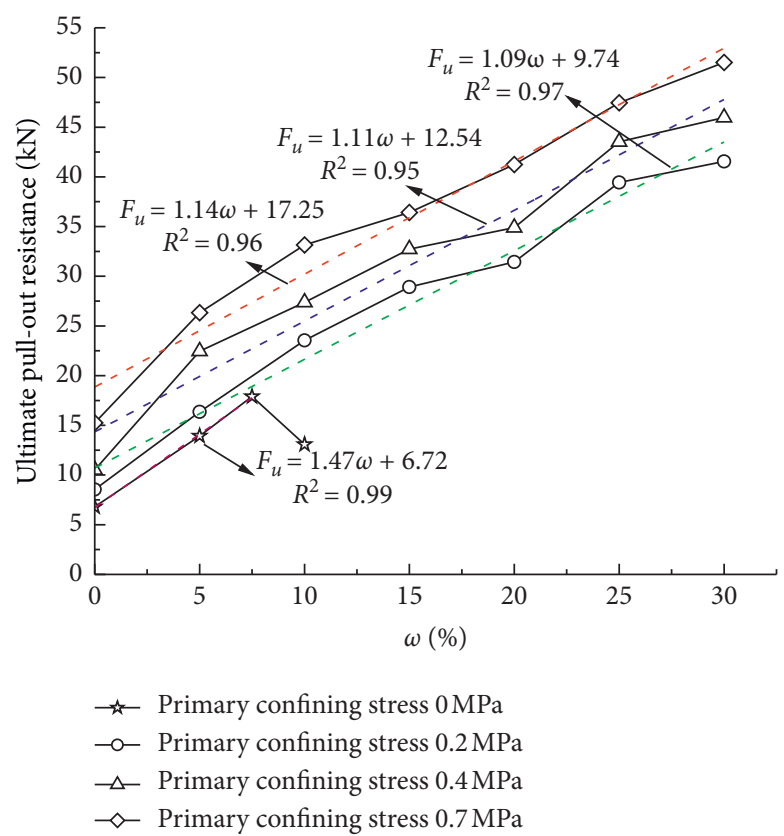

Figure 18: Variation of ultimate pull-out resistance with the expansion agent content under different initial confinement schemes. 
It is shown that there is an obvious linear relationship between the ultimate pull-out capacity and the content of the expansion agent under the same initial lateral limit, as shown in Figure 18, which can be expressed as:

$$
F_{u}=A \omega+B \text {. }
$$

A represents the growth factors of the unit expansion agent content to the ultimate pull-out capacity, and B represents the initial ultimate pull-out capacity when $\omega=0$.

Statistics of the ultimate pull-out capacity growth factors $A$ and the initial ultimate pull-out force B under each initial confinement condition are found to be related to the initial confinement. The relationship curve is shown in Figure 19.

The initial confinement of the ultimate pull-out capacity growth factors A can be expressed by a relationship of indices, which is shown as follows:

$$
A=\alpha e^{p_{0}}+\beta .
$$

In the formula, $\alpha$ represents the influence factors of the initial confinement on the growth factors $\mathrm{A}, \mathrm{P}_{0}$ represents the initial confinement stress value, and $\beta$ represents the corresponding initial growth factors when $P_{0}=0$.

The initial ultimate pull-out capacity $B$ and the initial confining stress can be expressed by a linear relationship.

$$
B=\gamma P_{0}+\zeta
$$

In the formula, $P_{0}$ is the initial confining stress value, $\gamma$ is the influence factors of the initial confining stress on the initial ultimate pull-out capacity, and $\zeta$ is the initial growth constant.

Substituting formula (9) and formula (16) into formula (8) to sort out the expressions of ultimate pull-out capacity, expansion agent content, and initial confinement, we obtain

$$
F_{u}=\alpha \omega e^{p_{0}}+\beta \omega+\gamma p_{0}+\zeta .
$$

From formula (11), it can be seen that $P_{0}$ has an exponential influence on $F_{u}$, which means that adjusting the initial confining stress has a more significant influence on the ultimate pull-out capacity. In the engineering application, the surrounding rock conditions with good confinement constraints should be selected to give full play to the role of the expansion agent.

\section{Research on Mechanical Characteristics of Anchor Bolt Interface under the Influence of the Surrounding Rock Stress}

\subsection{Establishment of Interface Mechanics Model under the Influence of Surrounding Rock Stress}

5.1.1. Self-Expansion Effect Parameter Introduction. The force state of the self-expanding anchor rod is shown in Figure 20.

Considering the expansion effect, the forces on the three main bodies and the two interfaces have changed. Based on the distribution law of bolt shear stress along the rod body proposed by Chun-an [38],

$$
\tau_{(x)}=\frac{p}{\pi a} \frac{t x}{2} \exp \left(\frac{-t}{2}\right) x^{2} .
$$

Adding $t=(1 /((1+\mu)(3-2 \mu)))\left(E / E_{a}\right)$ and introducing the self-expansion effect coefficient, we obtain the following:

(1) Since the use of the self-expanding anchorage material has a significant influence on the ultimate pullout force, the self-expanding influence coefficient $\lambda$ is introduced before the drawing load $P$, which can reflect the efficiency of interfacial shear force transmission to the depth along the rod body.

(2) Considering the influence of surrounding rock stress on the anchorage system, multiplying the whole by the surrounding rock stress influence coefficient $k$, and its physical meaning is the improvement rate of surrounding rock confined stress on the anchorage performance.

(3) Compared with ordinary anchor solids, the slip section generated by the bolt in the self-expanding anchor solids changes, resulting in the introduction of the slip coefficient $\gamma$, the physical meaning of which is the suppression of the sliding of the anchor rod by the self-expanding effect.

(4) Poisson's ratio and elastic modulus of the surrounding rock and anchor are changed due to the expansion stress applied to the surrounding rock, resulting in the introduction of the deformation correction coefficient $\xi$, the physical meaning of which is the influence rate of the unit expansion agent content on the composite deformation parameter $t$ of the bolt-surrounding rock.

5.1.2. Shear Force Model Establishment. The shear stress formula of the bolt interface under the self-expanding additional stress is as follows:

$$
\tau_{(x)}=k \frac{\lambda p}{\pi a}(x+\gamma) \frac{t}{2} \exp \left(\frac{-\xi t}{2}(x+\gamma)^{2}\right) .
$$

Adding $t=(1 /((1+\mu)(3-2 \mu)))\left(E / E_{a}\right)$, we obtain $E_{\mathrm{a}}$ is the elastic modulus of the bolt, $E$ is the elastic modulus of the rock mass, $\mu$ is Poisson's ratio of the rock mass, and $a$ is the radius of the bolt.

5.1.3. Axial Force Model Establishment. The anchor rod axial force formula is calculated by integrating the shear stress formula on the anchoring length and multiplying the circumferential circumference of the anchor rod.

$$
N=\pi d_{a} \int \tau_{(x)} \mathrm{d}_{x}
$$

The formula of the anchor bolt axial force of the highstrength, precompressed anchor system under different surrounding rock stresses is gotten by integrating formula (18) on the anchorage length. 


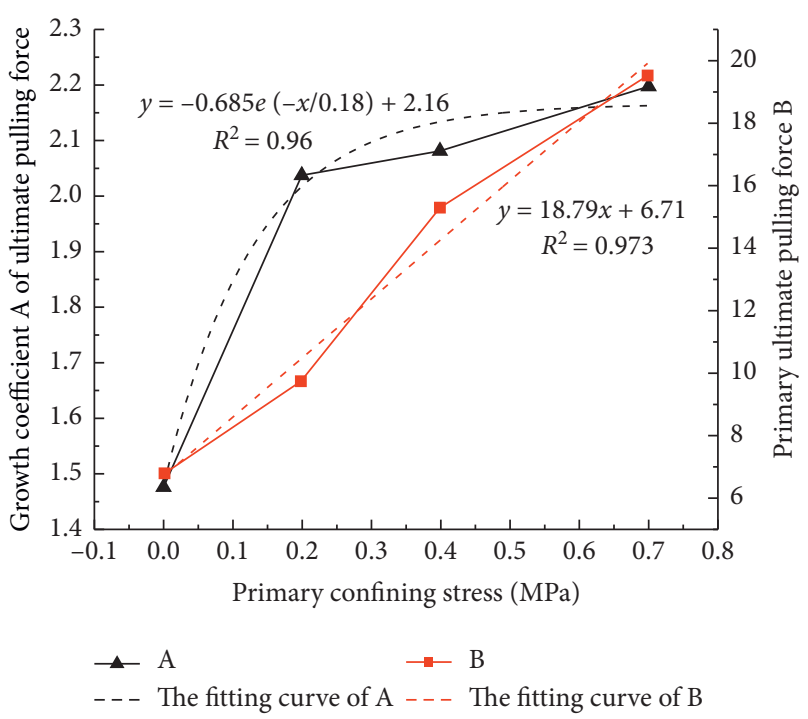

FIgURE 19: Relationship curves between the ultimate pull-out force growth factors. (a) The initial ultimate pull-out force. (b) The initial limit.

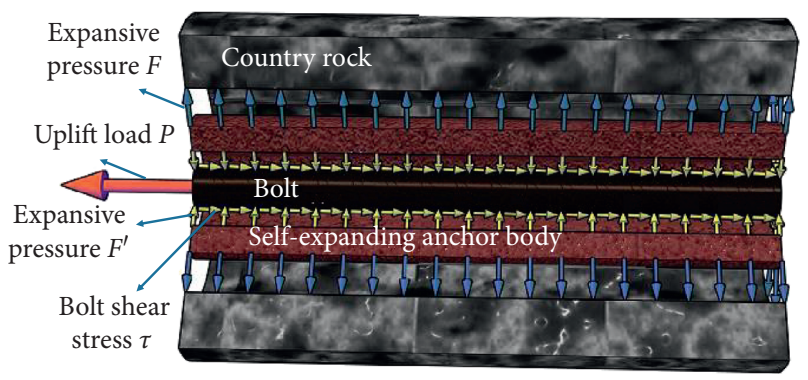

Figure 20: Forced state diagram of self-expanding anchor.

$$
N=k \frac{\lambda}{\xi} P \exp \frac{-\xi t}{2}(x+\gamma)^{2}
$$

5.2. Solving the Influence Coefficient of Self-Expansion Effect. According to the basic principle of the least square method, the test data are imported into MATLAB for fitting. The value of the stress influence coefficient $k$ of the surrounding rock under different initial confining stresses is shown in Table 3. The value of $\lambda$, $\gamma$, and $\xi$ corresponding to different expansion agent content is shown in Table 4 .

There is a good exponential relationship between the surrounding rock stress influence coefficient $k$ and the initial confining stress $p_{0}$ by analyzing the dates in Table 3 . The expression is as follows:

$$
K=0.952 \exp 1.089 P_{0},
$$

where 0.952 and 1.089 are influence parameters of $K$ in the formula, when the initial confining stress $P_{0}=0$ and $K=0.952$.

From the analysis of Table 4 the following inferences can be made:
(1) We can see that the self-expansion influence parameter $\lambda$ tends to decrease with the increase of the expansion agent content. The expression can be written as:

$$
\lambda=-1.985 \times 10^{-4} \omega+0.273 .
$$

The number of $-1.985 \times 10^{-4}$ is the attenuation coefficient of the expansion agent content on the selfexpansion parameter $\lambda$. The number of 0.273 is the self-expansion influence parameter when $\omega=0$.

The parameter $\lambda$ is less than 1 . The transmission capacity of the axial force along the length of the rod is reduced, which causes the shear stress to be concentrated at the front end. And this phenomenon is intensified with the increase of the expansive agent content.

(2) The slip coefficient $\gamma$ is negative. The difference between $\omega=5$ and $\omega=30$ is only $0.304 \%$. Therefore, the dosage is not very sensitive to coefficient $\omega$, and the number of -9.288 is taken as the slip coefficient $\gamma$.

(3) The deformation correction coefficient $\xi$ depends on Poisson's ratio and elastic modulus of the surrounding rock mass, anchor solid, and rod body. The self-expansion effect caused by different contents of expansion agent makes Poisson's ratio and elastic modulus of surrounding rock mass and anchor solid different.

(4) The deformation correction coefficient $\xi$ and the content can be described by a linear function; the specific expression is as follows:

$$
\xi=-2.21 \times 10^{-3} \omega+0.539 .
$$

In the formula, the number of $-2.21 \times 10^{-3}$ is the influence coefficient of the expansion agent content on the deformation correction coefficient $\lambda$. The number of 0.539 is the deformation correction coefficient when $\omega=0$.

\subsection{Analysis and Verification of Calculation Examples.} The slightly weathered sandstone of a slope in the Three Gorges Reservoir area is selected as the surrounding rock in this experiment, with the elastic modulus and Poisson's ratio of $1.2 \times 10^{4} \mathrm{MPa}$ and 0.3 , respectively. The bolt is made of threaded steel with a diameter of $20 \mathrm{~mm}$, and the elastic modulus of the bolt is $2.1 \times 10^{5} \mathrm{MPa}$. Considering that the initial confining stress is $0.7 \mathrm{MPa}, \omega=0$ and $\omega=20$, the comparison between the calculated values of the shear stress and the axial force formula and the measured value with the anchoring depth is shown in Figures 21 and 22.

From Figures 21 and 22, the following inferences can be made:

(1) It can be obtained that the axial force and shear force of the anchor rod with different contents of the expansion agent under different ground stresses calculated by the formula are in good agreement with 
TABLE 3: Table of values for the influence coefficient $k$ of surrounding rock stress under different initial confined stresses.

\begin{tabular}{llcr}
\hline \multirow{2}{*}{ Affecting parameters of surrounding rock stress } & \multicolumn{3}{c}{ Initial confining stress $(\mathrm{MPa})$} \\
& 0 & 0.2 & 0.4 \\
\hline$k$ & 1 & 1.118 & 0.7 \\
\hline
\end{tabular}

TABLe 4: Values of $\lambda, \gamma$, and $\xi$ under the dosage of each expansion agent.

\begin{tabular}{|c|c|c|c|}
\hline \multirow{2}{*}{ Expansion agent content (\%) } & \multicolumn{3}{|c|}{ Influence parameters } \\
\hline & Self-expansion influence parameter $\lambda$ & Slip parameter $\gamma$ & Deformation correction function $\xi$ \\
\hline 0 & 0.271648 & -9.288144 & 0.544392 \\
\hline 5 & 0.270284 & -9.289057 & 0.527364 \\
\hline 10 & 0.269637 & -9.288351 & 0.512345 \\
\hline 15 & 0.269156 & -9.288067 & 0.509621 \\
\hline 20 & 0.267365 & -9.288169 & 0.485334 \\
\hline 25 & 0.266845 & -9.287024 & 0.483225 \\
\hline 30 & 0.265436 & -9.286227 & 0.479753 \\
\hline
\end{tabular}

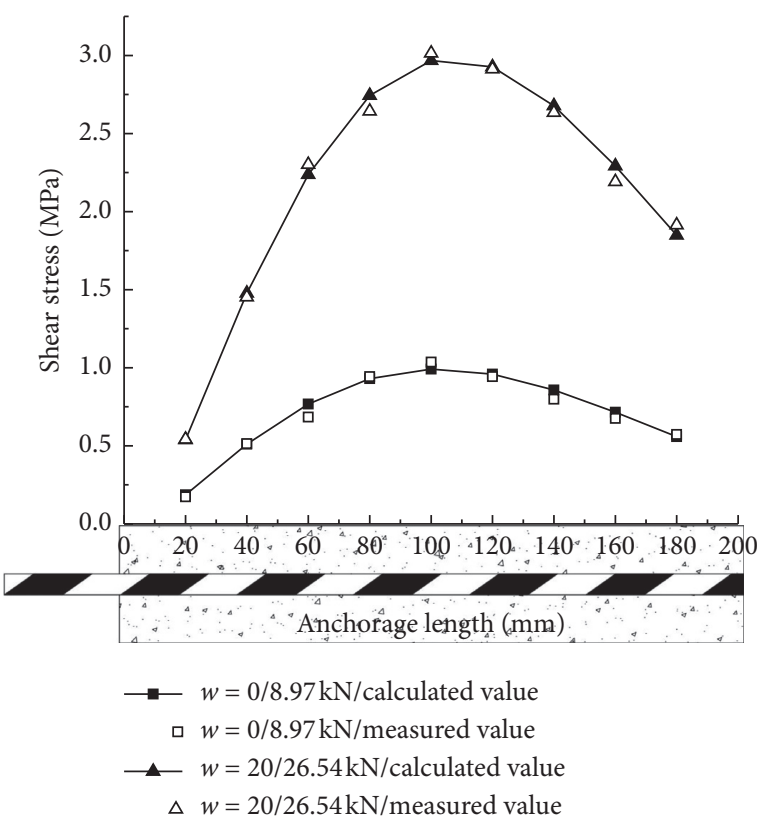

Figure 21: Comparison of measured and calculated shear stress.

the measured values after introducing the self-expansion effect parameters, which proves the feasibility of the formula.

(2) The shear stress distribution law is similar, which shows a trend of first increasing and then decreasing with the anchoring length. It is found that the shear stress at $20 \mathrm{~mm}$ is increased by 2.89 times compared with 0 content when $\omega=20$, indicating that the shear stress is more concentrated at the front end of the anchor.

(3) The distribution of axial force shows a decay trend and is not evenly distributed along the bolt. It is concluded that the axial force at the same interface can increase by at least 2.83 times when $\omega=20$ compared with $\omega=0$. It shows that the expansion



Figure 22: Comparison of measured and calculated axial force.

pressure greatly increases the strength of the interface between the anchor rod and the anchor, and the ultimate pull-out resistance is significantly enhanced.

\section{Energy Analysis Based on Different Self- Expansion Pressures}

6.1. Establishment of the Energy Equation. In order to quantitatively analyze the influence of the expansion agent content on the deformation and failure process of anchor solids, the concept of energy is introduced. And the influence of the expansion agent content on the failure characteristics and ultimate pull-out resistance of the anchor system is quantitatively analyzed from the law of energy change. 
Assuming that the self-expanding anchor pull-out test is a closed system without heat exchange with the outside, the applied external forces include axial force, shear stress, selfweight, surrounding rock stress, and expansion pressure. Taking the unit volume anchor unit as an example, the axial force of the anchor unit is shown in Figure 23. The work done by the pulling load $P$ on the anchor rod is the product of $\mathrm{P}$ and the top displacement $X_{0}$ of the anchor rod under its action. At the same time, the anchor solid and the surrounding rock and soil are relatively displaced, resulting in deformation energy, potential energy, and the center of gravity changes under the action of $P$.

Therefore, the sum of the work done by the external force on the unit body is shown in the following formula:

$$
\begin{aligned}
W_{p}= & \sigma_{i} \pi a^{2} l_{i}-m g \frac{\left(l_{i}+l_{i+1}\right)}{2}-\sigma_{i+1} \pi a^{2} l_{i+1} \\
& -2 \pi a \int_{I}^{i+1} \tau_{x} l_{x} \mathrm{~d} x .
\end{aligned}
$$

In the formula, $l_{\mathrm{i}}$ is the displacement of the upper end of the element and $l_{\mathrm{i}+1}$ is the displacement of the lower end of the element.

The strain energy increment of the selected element is shown in the following formula:

$$
V_{\varepsilon}=\frac{E A}{2 \delta l}\left(l_{i}-l_{i+1}\right)^{2}
$$

The strain energy accumulated in the elastic body is equal in value to the work done by the external force. The energy equation of the bolt body is as follows:

$$
\begin{aligned}
\frac{E A}{2 \delta l}\left(l_{i}-l_{i+1}\right)^{2}= & \sigma_{i} \pi a^{2} l_{i}-\frac{1}{2} m g\left(l_{i}+l_{i+1}\right)-\sigma_{i+1} \pi a^{2} l_{i+1} \\
& -2 \pi a \int_{i}^{i+1} \tau_{x} l_{x} \mathrm{~d} x .
\end{aligned}
$$

As for the bolt-combining the law of axial force transmission of the anchor body and simplifying the function relationships, the total amount of work done by the external force is shown in the following formula:

$$
W_{p}=m g x_{0}+2 \pi a \int_{0}^{l} \tau_{x} l_{x} \mathrm{~d} x .
$$

The strain energy includes the elastic potential energy increment of the anchored section and the deformation potential energy of the free section.

$$
W_{\varepsilon}=\frac{1}{2} E A \int_{0}^{l}\left(\frac{\mathrm{d} x_{i}}{\mathrm{~d} x}\right)^{2} \mathrm{~d} x+\frac{P^{2} L_{f}}{2 E A} .
$$

In the formula, $L_{f}$ is the length of the free section of the anchor rod.

The energy consumption of the entire anchor rod under the action of the pulling load $P$ can be obtained by comprehensive formulas (8), (18), (19).

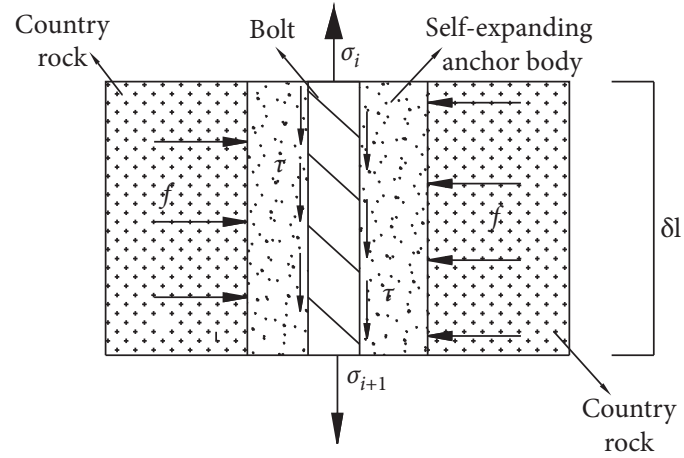

FIGURE 23: Schematic diagram of the axial force of the anchor unit.

$$
\begin{aligned}
W_{C}= & m g x_{0}+K \lambda P t \int_{0}^{l}(x+\gamma) \exp \left(\frac{-\xi t(x+\gamma)^{2}}{2}\right) x_{i} \mathrm{~d} x \\
& +\frac{1}{2} E A \int_{0}^{l}\left(\frac{\mathrm{d} x_{i}}{\delta l_{i}}\right)^{2} \mathrm{~d} x+\frac{P^{2} L_{f}}{2 E A} .
\end{aligned}
$$

On analyzing formula (20), the following inferences can be made:

(1) It can be seen that the work done by the pull-out loading $P$ can be converted into four forms of energy, including gravitational potential energy, interface shear work, elastic energy of the anchoring section, and deformation energy of the free section. It is believed that the higher the energy consumption of the bolt, the stronger the supporting capacity.

(2) Due to the influence of the self-expansion effect, the shear stress is more concentrated on the front end of the anchor, and the transmission ability to the deep part is reduced, which means that the energy of the self-expanding anchor system is more converted into the elastic energy of the anchor section and the deformation energy of the free section under the same pull-out force.

6.2. Energy Equation Calculation Example. The elastic modulus and Poisson's ratio of the surrounding rock in this test are $1.2 \times 10^{4} \mathrm{MPa}$ and 0.3 , respectively. The anchor rod is made of threaded steel with a diameter of $20 \mathrm{~mm}$, the elastic modulus of which is $2.1 \times 10^{5} \mathrm{MPa}$, the mass per unit length is $2.47 \mathrm{~kg}$, the anchoring section length is $200 \mathrm{~mm}$, and the free section length is $400 \mathrm{~mm}$. Taking $\omega=0$ and $\omega=30$ in the initial confinement $P_{0}=0.7 \mathrm{MPa}$ scheme to calculate, and the corresponding load-displacement curve is shown in Figure 24.

It can be seen from Figure 24 that the corresponding ultimate pull-out resistance and the displacement of the anchor rod before the peak are $15.25 \mathrm{kN}, 11.28 \mathrm{~mm}$ and $51.52 \mathrm{kN}, 23.43 \mathrm{~mm}$, respectively.

Firstly, by substituting the initial confining stress $P_{0}=0.7 \mathrm{MPa}, \omega=0, \omega=30$ into formulas (12)-(14), respectively, we can get $K=2.04, \lambda_{0}=2.73, \lambda_{30}=2.67$, and 


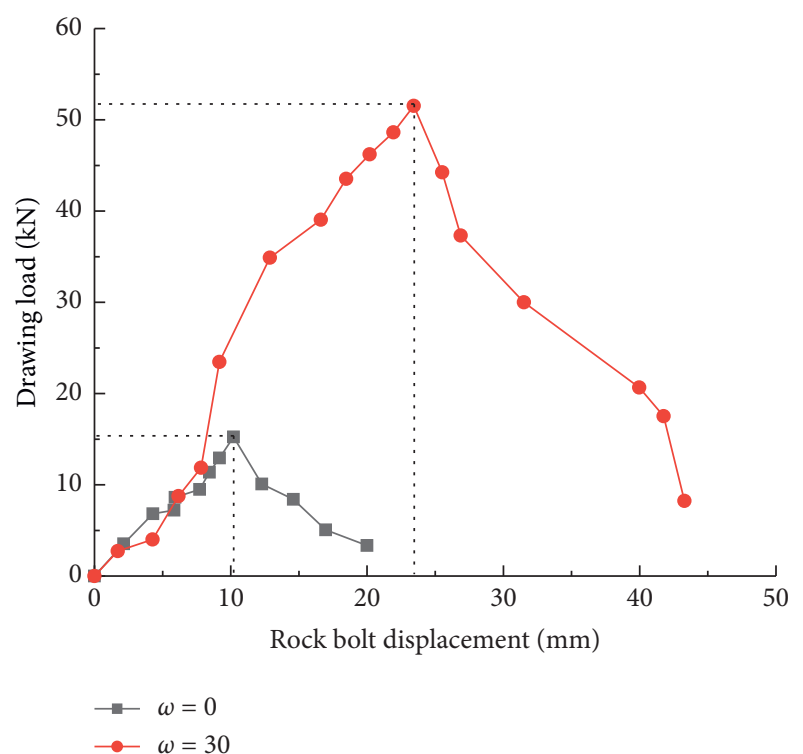

FIGURE 24: Load-displacement curve of the example.

$\xi_{0}=0.539, \xi_{30}=0.473$. Substituting the data into formula thirty, we can get $W_{\mathrm{C} 30}=1352.99 \mathrm{~J}, W_{\mathrm{C} 0}=184.44 \mathrm{~J}$, and $W_{C 30} / W_{C 0}=1352.99 / 184.44=7.34$. In the same external conditions, the supporting capacity of the self-expanding anchoring system is 7.34 times higher than that of the ordinary bolt under the action of the ultimate drawing load.

Based on the literature [39], the rock anchor beam position of the underground powerhouse of a hydropower station was calculated. There are four rows of long anchor rods, with diameter of $32 \mathrm{~mm}$, and the arrangement spacing is $0.75 \mathrm{~m} \times 0.75 \mathrm{~m}$. The length of the upper two rows of tension bolts is $12 \mathrm{~m}$, and the elevation angles are $20^{\circ}$ and $15^{\circ}$, respectively. The length of the middle row of horizontal bolts is $9 \mathrm{~m}$. The length of the bottom row of compression bolts is $9 \mathrm{~m}$, and the inclination angle is $55^{\circ}$. The diameter of anchor hole is $90 \mathrm{~mm}$. Huaxin brand 42.5 portland cement has been used, and the unit price is 380 yuan/ton. Changsha Jiaze brand static rock cracking expansion agent is used as the expansion agent, and the unit price is 2,100 yuan/ton. According to calculations, the cost of self-expanding anchoring support only increased by $0.023 \%$.

\section{Conclusion}

(1) A device for rock mass anchoring under simulated in situ stress conditions has been developed, which can realize independent loading of two-way reaction forces and stress locking, while ensuring no confined loss.

(2) According to the time evolution trend of the expansion stress, it is pointed out that the internal interface stress stabilization stage is the operation stage of the actual project. The coordinated additional stress is defined, and its temporal and spatial evolution law in the rock mass is obtained. It is found that there is an obvious time lag between the peak of the internal interface stress and the peak of the coordinated additional stress. Based on the initial confinement, the mechanical mechanism of the time lag of the peak of the coordinated additional stress is explained.

(3) Combining the drawing load-displacement curve, it is pointed out that the high-strength precompressed anchor system has a unique load platform effect. And the cause of the platform effect has been explained by the mechanical mechanism diagram.

(4) A prediction model for the ultimate pull-out force of the high-strength, precompressed anchor system is established. And, it is pointed out that the initial confined stress value has an exponential effect on the ultimate pull-out force, and the amount of the expansion agent has a linear effect on the ultimate pullout force.

(5) Based on the test results of the self-expansion effect of anchors, the self-expansion strengthening coefficient $\lambda$, the surrounding rock stress influence coefficient $k$, the slip coefficient $\gamma$, and the deformation correction coefficient $\xi$ are defined. The shear stress and axial force formulas of the bolt interface of the self-expanding anchor system are established, and the feasibility of the formulas is verified by the calculation examples.

(6) The energy equation of the high-strength preloaded anchor system is established. The energy evolution law is obtained. It is also pointed out that $\omega=30$ increases the ultimate pull-out resistance of anchorage with $\omega=0$ to 3.38 times under the initial confining stress condition of $0.7 \mathrm{MPa}$. The prepeak displacement of the bolt increases by 2.08 times. And, the prepeak energy consumption value of the anchoring system increases by 7.34 times. The cost of the case only increased by $0.023 \%$.

\section{Data Availability}

The test data are included within the article and are available from the corresponding author upon request.

\section{Conflicts of Interest}

The authors declare that they have no conflicts of interest regarding the publication of this paper.

\section{Acknowledgments}

This work was supported in part by the National Natural Science Foundation of China (NSFC) (grant nos. 51809151 and 52079071), the Natural Science Fund for Distinguished Young Talent Program in Hubei Province (grant no. 2018CFA065), the Natural Science Foundation Innovation Group in Hubei Province (grant no. 2020CFA049), and the 
Research Fund for Excellent Dissertation of China Three Gorges University (grant no. 2019SSPY026).

\section{References}

[1] A. Staniek, "Identification of discontinuities in resin layer of grouted rock bolts," Experimental Techniques, vol. 36, no. 2, pp. 12-23, 2012.

[2] Y.-S. Song, "Pull-out resistance characteristics of the anchor bar according to the grouting material," The Journal of Engineering Geology, vol. 18, no. 2, pp. 227-232, 2008.

[3] C. Ma, Y. Tan, E. Li, Y. Dai, and M. Yang, "High-performance grouting mortar based on mineral admixtures," Advances in Materials Science and Engineering, vol. 2015, Article ID 425456, 11 pages, 2015.

[4] C. Cao, T. Ren, Y. Zhang, L. Zhang, and F. Wang, "Experimental investigation of the effect of grout with additive in improving ground support," International Journal of Rock Mechanics and Mining Sciences, vol. 85, pp. 52-59, 2016.

[5] S.-c. Li, H.-t. Wang, Q. Wang et al., "Failure mechanism of bolting support and high-strength bolt-grouting technology for deep and soft surrounding rock with high stress," Journal of Central South University, vol. 23, no. 2, pp. 440-448, 2016.

[6] J. S. Tian and L. Hu, "Anchorage performance of a highpressure pre-tightening resin anchor with a compressed grouting body," PLoS One, vol. 12, no. 2, 2017.

[7] J. Park, T. Kim, and B. Lee, "Evaluation of reinforcement effects according to reinforcement type and grouting method," Journal of The Korean Geoenvironmental Society, vol. 20, no. 8, pp. 13-20, 2019.

[8] F. Wang, C. Zhang, S. Wei, X. Zhang, and S. Guo, "Whole section anchor-grouting reinforcement technology and its application in underground roadways with loose and fractured surrounding rock," Tunnelling and Underground Space Technology, vol. 51, pp. 133-143, 2016.

[9] J. Park, T. Qiu, and Y. Kim, "Field and laboratory investigation of pullout resistance of steel anchors in rock," Journal of Geotechnical and Geoenvironmental Engineering, vol. 139, no. 12, pp. 2219-2224, 2013.

[10] C. C. Li, "A new energy-absorbing bolt for rock support in high stress rock masses," International Journal of Rock Mechanics and Mining Sciences, vol. 47, no. 3, pp. 396-404, 2010.

[11] G. Wang, X. Wu, Y. Jiang, N. Huang, and S. Wang, "Quasi-static laboratory testing of a new rock bolt for energy-absorbing applications," Tunnelling and Underground Space Technology, vol. 38, pp. 122-128, 2013.

[12] Y. Wang, Z. Dong, L. Wei, and F. Lei, "Experimental research on destruction mode and anchoring performance of carbon fiber phyllostachys pubescens anchor rod with different forms," Advances in Civil Engineering, vol. 2018, Article ID 1841267, 14 pages, 2018.

[13] J. Cao, N. Zhang, S. Wang, D. Qian, and Z. Xie, "Physical model test study on support of super pre-stressed anchor in the mining engineering," Engineering Failure Analysis, vol. 118, 2020.

[14] K.-C. Kim, H.-J. Kim, Y.-H. Jung, and J.-H. Shin, “Anchorage mechanism of inflatable steel pipe rockbolt depending on rock stiffness," Journal of Korean Tunnelling and Underground Space Association, vol. 19, no. 2, pp. 249-263, 2017.

[15] T. L. Xiao and Y. L. He, "Experimental study of an inflatable recyclable anchor," Advances in Materials Science and Engineering, vol. 2018, Article ID 6940531, 10 pages, 2018.
[16] B. X. Yuan, L. Xiong, L Zhai et al., “Transparent synthetic soil and its application in modeling of soil-structure interaction using optical system," Frontiers in Earth Science, vol. 7, 2019.

[17] B. X. Yuan, M. Sun, L. Xiong, Q. Z. Luo, S. P. Pradhan, and H. Z. Li, "Investigation of 3D deformation of transparent soil around a laterally loaded pile based on a hydraulic gradient model test," Journal of Building Engineering, vol. 28, no. 3, 2020.

[18] X. Wu, Y. Jiang, G. Wang, B. Gong, Z. Guan, and T. Deng, "Performance of a new yielding rock bolt under pull and shear loading conditions," Rock Mechanics and Rock Engineering, vol. 52, no. 9, pp. 3401-3412, 2019.

[19] P. K. Tae and S. J. Kwon, "Experimental study on tensionhardening and softening characteristics in reinforced mortar with CSA expansion agent," Journal of The Korea Institute for Structural Maintenance and Inspection, vol. 18, no. 1, pp. 101-110, 2014.

[20] S. Nagataki and H. Gomi, "Expansive admixtures (mainly ettringite)," Cement and Concrete Composites, vol. 20, no. 2-3, pp. 163-170, 1998.

[21] S. H. Liu and K. H. Fang, "Study on autogenous deformation of concrete incorporating $\mathrm{MgO}$ as expansive agent," Key Engineering Materials, vol. 302-303, pp. 155-161, 2006.

[22] L. Mo, M. Deng, and M. Tang, "Effects of calcination condition on expansion property of MgO-type expansive agent used in cement-based materials," Cement and Concrete Research, vol. 40, no. 3, pp. 437-446, 2010.

[23] H. Li, J. Liu, Y. Wang, and Q. Tian, "Simplified chemomechanical model of hydration/expansion of calcium-oxidetype expansive agent in cement-based materials," Magazine of Concrete Research, vol. 72, no. 19, pp. 1006-1015, 2020.

[24] Z. Pan, Y. Zhu, D. Zhang, N. Chen, Y. Yang, and X. Cai, "Effect of expansive agents on the workability, crack resistance and durability of shrinkage-compensating concrete with low contents of fibers," Construction and Building Materials, vol. 259, 2020.

[25] H. M. Cheol, "Estimation of the autogenous shrinkage of the high performance concrete containing expansive additive and shrinkage reducing agent," Journal of the Korea Institute of Building Construction, vol. 7, no. 3, pp. 123-130, 2007.

[26] M. S. Meddah, M. Suzuki, and R. Sato, "Influence of a combination of expansive and shrinkage-reducing admixture on autogenous deformation and self-stress of silica fume highperformance concrete," Construction and Building Materials, vol. 25, no. 1, pp. 239-250, 2011.

[27] P. Shen, J. X. Lu, H Zheng et al., "Expansive ultra-high performance concrete for concrete-filled steel tube applications," Cement \& Concrete Composites, vol. 114, 2020.

[28] P.-w. Gao, S.-x. Wu, P.-h. Lin, Z.-r. Wu, and M.-s. Tang, "The characteristics of air void and frost resistance of RCC with fly ash and expansive agent," Construction and Building Materials, vol. 20, no. 8, pp. 586-590, 2006.

[29] H. Q. Ma, H. G. Zhu, H. Y. Chen, Y. D. Ni, X. N. Xu, and Q. J. Huo, "Shrinkage-reducing measures and mechanisms analysis for alkali-activated coal gangue-slag mortar at room temperature," Construction and Building Materials, vol. 252, 2020.

[30] J. Guo, S. Zhang, T. Guo, and P. Zhang, "Effects of UEA and $\mathrm{MgO}$ expansive agents on fracture properties of concrete," Construction and Building Materials, vol. 263, 2020.

[31] M. Wyrzykowski, G. Terrasi, and P. Lura, "Expansive highperformance concrete for chemical-prestress applications," Cement and Concrete Research, vol. 107, pp. 275-283, 2018. 
[32] R. V. De. Silva, R. P. Gamage, and M. S. A. Perera, "An alternative to conventional rock fragmentation methods using SCDA: a review," Energies, vol. 9, no. 11, 2016.

[33] V. R. S. De Silva., P. G. Ranjith, M. S. A. Perera, B. Wu, and T. D. Rathnaweera, "The influence of admixtures on the hydration process of soundless cracking demolition agents (SCDA) for fragmentation of saturated deep geological reservoir rock formations," Rock Mechanics and Rock Engineering, vol. 52, no. 2, pp. 435-454, 2019.

[34] H. Cho, Y. Nam, K. Kim, J. Lee, and D. Sohn, "Numerical simulations of crack path control using soundless chemical demolition agents and estimation of required pressure for plain concrete demolition," Materials and Structures, vol. 51, no. 6, 2018.

[35] V. R. S. De Silva., P. G. Ranjith, M. S. A. Perera, and B. Wu, "The effect of saturation conditions on fracture performance of different soundless cracking demolition agents (SCDAs) in geological reservoir rock formations," Journal of Natural Gas Science and Engineering, vol. 62, pp. 157-170, 2019.

[36] V. R. S. De Silva., P. G. Ranjith, M. S. A. Perera, B. Wu, and W. A. M. Wanniarachchi, "A low energy rock fragmentation technique for in-situ leaching," Journal of Cleaner Production, vol. 204, pp. 586-606, 2019.

[37] S. Xu, P. Hou, R. Li, and M. Cai, "An experimental study on the mechanical properties and expansion characteristics of a novel self-swelling cartridge for rock breakage," Rock Mechanics and Rock Engineering, 2020.

[38] Y.. Chun'an, "Mechanical analysis on wholly grouted anchor," Chinese Journal of Rock Mechanics and Engineering, vol. 19, no. 3, pp. 339-341, 2000.

[39] Z.. Hao, X.. Ming, C. J. Tao, and L. G. Qing, "Numerical simulation of long bolts for crane beam anchored in rock in underground powerhouse," Chinese Journal of Rock Mechanics and Engineering, vol. 35, no. 12, pp. 2439-2451, 2016. 